\title{
1 Meso-scale aeolian sediment input to coastal dunes: The nature of aeolian
}

2 transport events

4 Irene Delgado-Fernandez, Robin Davidson-Arnott

5 Department of Geography, University of Guelph, Guelph, ON, Canada

7 Abstract

8 Observations of aeolian transport in coastal areas have focused on short-term

9 experiments because of limitations imposed by instrumentation. This paper uses a

10 case study at Greenwich Dunes, Prince Edward Island National Park, Canada, to

11 analyze how sediment transport takes place at the beach over periods of weeks to months. A monitoring station provided hourly time series of vegetation cover, shoreline position, fetch distances, surficial moisture content, presence of ice and snow, wind speed and direction and transport processes over nine months. Analysis shows that high wind speeds may not generate any net transport into the dunes because of the limitations imposed by snow/ice cover, moisture, and short fetch distances. Despite extreme winds during intense storms, such events often lead to wave scarping rather than aeolian sediment input to the foredunes. When sediment was transported on the beach, the magnitude was regulated by a combination of factors including: angle of wind approach, fetch distance, moisture content, and duration of the wind event. In particular, angle of wind approach (and therefore fetch distance) may demote a high magnitude wind event with strong transport potential to one with no transport at all, which poses challenges for predicting the effects of

24 individual storms over the course of several months. A significant proportion of sediment delivery to the foredunes was associated with wind events of low to 
medium magnitude. It is suggested here that large magnitude wind events have low probabilities of resulting in transport towards the foredune because factors such as wave inundation play an increasing role in preventing sediment movement across the beach. This has implications for modelling and management, and highlights differences between the magnitude and frequency of aeolian transport events in the coastal environment compared to those in deserts and to fluvial sediment transport.

\section{Keywords}

Meso-scale; Event frequency; Event magnitude; Foredune budget

\section{Introduction}

37

As in many other landscapes, coastal dunes evolve as a consequence of both gradual changes in state variables (e.g., vegetation growth or decay) as well as episodic event-based disturbances (e.g., wave scarping) (Pye, 1983 and Psuty, 2005). In particular, sediment input by wind from the beach to the adjacent foredunes is intermittent both at the instantaneous (Stout and Zobeck, 1997) and medium scales (Delgado-Fernandez and Davidson-Arnott, 2009). Knowledge of sand transport by wind is essential for sediment budget calculations because it produces an output of sediment from the beach and constitutes the primary source of sediment supply for building the dune (Svasek and Terwindt, 1974 and Davidson-Arnott et al.,

47 2005). Therefore, understanding the characteristics of aeolian transport events in coastal areas is necessary to predict the evolution of coastal dunes.

The role of transport events and their relation to morphological change has been

50 widely recognized in geomorphology (Higgitt and Lee, 2001). In general terms, 
51 magnitude and frequency of events are inversely related. Stronger river flows, for example, which have the potential to carry large sediment loads, tend to occur less frequently. Thus, the significance of high magnitude events in terms of the proportion

54 of 'geomorphic work' accomplished may be quite small in comparison to events of 55 intermediate magnitude and frequency that are thought to dominate the fluvial 56 landscape (Wolman and Miller, 1960).

57 Knowledge about the characteristics of aeolian transport events contributing to the long-term evolution of coastal dunes is surprisingly limited. Time series of sediment transport for river flows are available from a variety of monitoring stations world-wide over long periods of time, but there are no equivalent records for aeolian transport in coastal areas. This poses several challenges for coastal aeolian geomorphology.

62 First, the lack of sediment transport time series at the same time resolution and duration as wind records makes it difficult to assess the relative significance of wind events of different magnitude. Prediction of sediment supply to the foredunes is often based on hourly data of wind speed and direction from meteorological stations along the coast that are incorporated into one of many alternative sediment transport models that presume ideal conditions on the beach (e.g., Chapman, 1990 and Miot da Silva and Hesp, 2010). Sediment transport calculations at meso-scales typically assume a correspondence between applied stress (wind speed) and sediment transport rate, and this may be modified by the cosine of the angle of wind approach in order to account for sediment supply to the foredune per unit distance alongshore

72 (Davidson-Arnott and Law, 1996 and Bauer and Davidson-Arnott, 2003). Second, there is a spectrum of problems associated with 'up scaling' results from short-term

74 experiments. The goal of many fieldwork studies is to observe significant events 75 where landform units are modified and forces affecting their evolution can be 
measured and quantified. But even when a number of geomorphic processes are characterized in detail over the course of a short-term experiment, traditional experimental designs produce knowledge based on 'snapshots', and thus miss the transition from one scale to another (Coulthard, 2009). This lack of a comprehensive view on the dynamics of aeolian sediment transport, beyond the duration of shortterm experiments, is a major limitation to providing managers and planners with an appropriate set of tools for decision-making (Sherman, 1995).

The recent incorporation of remote sensing techniques to measure aeolian processes at the beach over long periods of time (months to years) has enabled the direct observation of transport rather than relying on inference derived from morphological evidence (e.g.,Lynch et al., 2008 and Delgado-Fernandez et al., 2009). The importance of this type of approach is that it allows matching time series of wind speed and direction with observations and measurements of sediment transport on the beach at the same time-scale.

The main objective of this paper is to characterize the magnitude and frequency of aeolian transport events on the beach and to assess their role in supplying sediment for foredune building using a data set collected with a remote sensing station at Greenwich Dunes, Prince Edward Island National Park (Canada). The questions addressed here are: 1 . how do the frequency and magnitude of transport events compare with the frequency and magnitude of the associated wind events?; and 2. what is the effect of limiting factors such as moisture, fetch, snow and ice, and angle of wind approach? If the presence of other variables weakens the relationship between applied stress (wind) and the rate of sand transport, and if this can be generalized to most beach-dune systems, then the conceptual ideas put forward by Wolman and Miller (1960) may need to be adapted to the particular case of 
101 aeolian transport in coastal areas. Information about the characteristics of transport

102 events identified in the time series described here can provide a means of enhancing 103 our ability to model meso-scale sand supply to the foredune.

104 The first part of this paper deals with the characterization of the magnitude and 105 frequency of wind events or, in other words, with the nature of the applied stress at 106 Greenwich. The second part examines the characteristics of the corresponding 107 transport events over the study period.

108

\section{2. Regional setting}

111 Long-term monitoring of the beach and foredune was carried out at Greenwich

112 Dunes (Fig. 1A), located on the north shore of Prince Edward Island (PEI), Canada.

113 The measurements presented in this paper cover a section of the coast of

114 approximately $1.5 \mathrm{~km}$ in length. The foredune ranges in height from 6 to $10 \mathrm{~m}$ with a 115 steep stoss slope of $20-25^{\circ}$ and the dune crest is aligned roughly east-west. The 116 beach is $30-40 \mathrm{~m}$ wide and consists predominantly of quartz sand with a mean grain 117 diameter of $0.26 \mathrm{~mm}$. Marram grass (Amophila breviligulata) covers the foredunes 118 and exhibits considerable seasonal patterns of height and density. Summer months 119 are usually characterized by the development of a vegetated embryo dune which is 120 removed or strongly eroded every two or three years during Fall and Winter storms. 121 Monitoring of 9 profiles spaced along the $6 \mathrm{~km}$-long shoreline of Greenwich Dunes 122 from 2002 to 2009 showed an average net deposition of sand in the foredune of approximately $3500 \mathrm{~kg} \mathrm{~m}^{-1}$ year ${ }^{-1}$ with most deposition taking place during the Fall and early Winter period and very little deposition occurring during the summer

125 months from June to August. Spatially, net deposition was consistently lowest along 
126 the eastern end of the shoreline $\left(\approx 1250 \mathrm{~kg} \mathrm{~m}^{-1}\right.$ year $\left.^{-1}\right)$ and highest near the centre $127\left(\approx 6700 \mathrm{~kg} \mathrm{~m}^{-1}\right.$ year $\left.^{-1}\right)$. At the study site (white box in Fig. 1B) net deposition rates 128 were close to the average for the whole shoreline. Fig. 1C and D displays net annual 129 changes in deposition measured using a modified bedframe device (Davidson-Arnott 130 and Law, 1990 and Ollerhead et al., 2003) and morphological changes surveyed with 131 DGPS over a profile located within the study site (line W in Fig. 2). During the winters 132 of 2004 and 2008 intense storms resulted in erosion of the embryo dunes and cliffing of the foredune $\left(\approx-800\right.$ and $-6150 \mathrm{~kg} \mathrm{~m}^{-1}$ year $^{-1}$ respectively). Annual net

134 deposition during the rest of the years was approximately $5111 \mathrm{~kg} \mathrm{~m}^{-1}$, with a 135 maximum in $2006\left(\approx 9700 \mathrm{~kg} \mathrm{~m}^{-1}\right)$ and a minimum in $2003\left(\approx 1280 \mathrm{~kg} \mathrm{~m}^{-1}\right)$. Net 136 deposition from September 2007 to May 2008 was $\approx 3017 \mathrm{~kg} \mathrm{~m}^{-1}$. Thus the study 137 site is representative of medium volumetric changes both spatially and temporally and the period of observations presented in this paper is a year of average 139 deposition and storm events.

140 The coast is microtidal with a mixed semidiurnal regime and a maximum range at 141 spring tides of approximately $1 \mathrm{~m}$. Precipitation at PEI is abundant year-round.

142 Annual average totals are approximately $1000 \mathrm{~mm}$, with peaks from October to 143 January due to the more frequent and more intense storm activity. Wet days number 144130 to 160 a year, with snow days accounting for $30 \%$ of them. Ice covers much of 145 the Gulf of Saint Lawrence from January to early April, reducing the marine influence 146 and strongly affecting temperatures in PEI which may fall below $-18^{\circ} \mathrm{C}$. Drift ice is 147 often found around the Island as late as May and is subject to rapid movement as a 148 result of changing wind conditions (Environment Canada and Atlantic Climate 149 Center). During the 2007-2008 Winter the cameras at Greenwich recorded the 150 dynamics of sea ice, showing several periods of clearing from the nearshore during 
151 offshore winds (sometimes in less than $24 \mathrm{~h}$ ) and corresponding rapid build-up

152 during periods of onshore winds.

153 Prevailing winds from the SW and W occur predominantly in summer. These

154 offshore to alongshore winds are generally not competent to transport sediment to

155 the foredune despite their higher frequency (Walker et al., 2006). Fall and Winter

156 months are characterized by intense mid-latitude storms accompanied by strong

157 winds from the NE to the NW. Powerful North Atlantic storms with winds

$158>100 \mathrm{~km} \mathrm{~h}^{-1}$ have the potential to deliver large volumes of sediment to the dune but

159 they may also be accompanied by heavy rain or snowfall and storm surge. Further

160 information regarding the study site may be found in Walker et al., 2003, Hesp et al.,

161 2005, Davidson-Arnott et al., 2008 and Bauer et al., 2009.

162

163 3. Material and methods

164

165 3.1. Instrumentation, data collection and processing

166 The long-term monitoring station at Greenwich permits the acquisition of continuous

167 records of wind and beach characteristics that can be coupled with sand transport

168 measurements over periods of months. The experimental set up is described in

169 detail inDelgado-Fernandez et al. (2009) and only a brief description is given here.

170 Three 8-megapixel digital cameras were mounted on the top of a $6 \mathrm{~m}$-high mast on

171 the crest of the $8 \mathrm{~m}$ foredune (Fig. 2A). The cameras were controlled by a Mumford

172 Time Machine ${ }^{\mathrm{TM}}$ programmed to take pictures every hour on a continuous basis, with

173 the pictures stored on an internal memory card and downloaded every 2-3 months.

174 The camera looking to the east provided qualitative data on the overall beach,

175 weather and wave conditions over a distance of approximately $1.5 \mathrm{~km}$ alongshore. 
176 The offshore- and west-facing cameras covered distances of $40 \mathrm{~m}$ and $100 \mathrm{~m}$

177 alongshore, respectively. Wind speed and direction were measured using a

178 Windsonic 2-D sonic anemometer mounted at the top of the mast at a height of

179 approximately $14 \mathrm{~m}$ above the beach surface. The wind was sampled at $1 \mathrm{~Hz}$ on a

180 HOBO Energy Pro data logger with average values being stored every 2 min.

181 Sediment transport and deposition were measured using several different

182 techniques. Two Safire saltation probes which measure the impact of saltating sand

183 grains on a piezoelectric sensor (Baas, 2004) were deployed at foredune toe and at

184 the seaward edge of the embryo dune (Fig. 2B). Output from the Safires was

185 measured at $1 \mathrm{~Hz}$ and the average value stored every $2 \mathrm{~min}$. The height of the

186 Safires above the bed was initially set at $5 \mathrm{~cm}$ above the bed and was reset during

187 site visits approximately every two months. The sensors were sometimes buried by

188 sand for periods of time and the most seaward one was destroyed by the movement

189 of a large log along the beach during a storm on December 12, 2008 and was

190 replaced on February 20, 2009. Because of their deployment within the field of view

191 of the cameras, the continuity and quality of Safire records could be assessed from

192 the RGB images, which permitted the identification of times when the piezoelectric

193 sensor was buried as well as the height of the sensing area above the sand surface

194 when it was exposed.

195 Four erosion-deposition (ED) pins were deployed within the field of view of the 196 cameras (Fig. 2B). The ED pins consisted of wooden rods marked at $2 \mathrm{~cm}$ intervals

197 driven vertically into the sand surface. Changes in the level of the sand against the 198 rod could be measured with an accuracy of $1 \mathrm{~cm}$ on the hourly photographs to give a 199 profile of net change in the sand surface elevation. The volume of sediment 200 deposition along two survey lines across the stoss slope and toe of the foredune was 
measured every two to three months using a bedframe (Davidson-Arnott and Law,

2021990 and Ollerhead et al., 2003). A series of wooden posts were augered into the

203 sand along the profile and levelled forming permanent stations spaced 3-5 $\mathrm{m}$ apart.

204 Measurements of the distance to the bed at 12 points within a $1 \mathrm{~m} \times 1 \mathrm{~m}$ square

205 were made using a portable bedframe device consisting of an aluminum frame with

206 tabs to locate the measurement points. The bedframe has a square sleeve which

207 allows it to be slotted exactly over the $0.1 \mathrm{~m} \times 0.1 \mathrm{~m}$ top of the post and thus permits

208 repeated measurements at each station with a high degree of accuracy. The

209 bedframe is moved from station to station and stored away from the line. Net erosion

210 or deposition at a particular station is determined by averaging the measurements

211 made at the 12 points within the frame.

212 The images from the north and west cameras were rectified (Fig. 2B) based on a

213 model developed using 40-50 ground control points which were surveyed using a

214 Differential Global Position System (DGPS). The rectified images were then used to

215 derive information on beach surface moisture, snow and ice cover, vegetation cover

216 and the location of the shoreline. Maps of moisture content of the beach sand

217 surface (Fig. 2C) were derived from surface brightness recorded in the photographs

218 using a transfer function derived from in situ correlation between pixel brightness and

219 measurements of surface moisture ( McKenna Neuman and Langston, 2006, Darke

220 and McKenna Neuman, 2008 and Darke et al., 2009). Surface brightness

221 measurements were normalized against the brightness of whiteboard located within

222 the field of view of the cameras in order to account for changes in sun angle and

223 cloud cover (Delgado-Fernandez et al., 2009).

224 Vegetation was extracted from each image using an Unsupervised Classification

225 available as part of the Analysis extension from Leica Systems, which isolated pixels 
where vegetation was present. The 3D Analyst Tools was used to reclassify the

227 output into NoData values for all classes except the ones containing vegetation. The 228 shoreline was digitized manually for each photograph. Beach width was obtained 229 hourly from the position of the shoreline and the vegetation line. Storm surge, high 230 water levels, or spring tides (often in combination) strongly reduced beach width, 231 which also varied due to seasonal changes in the extent of embryo dune vegetation.

232 Beach width and mean angle of wind approach for a given hour were used to 233 calculate maximum fetch distances (Bauer and Davidson-Arnott, 2003).

234 Data were processed using a combination of ArcGIS 9.2, PCI Geomatica 9.1 and 235 Excel. A Geodatabase (PEI GDB) built with ArcCatalog was developed to store and 236 manage time series, following the guidelines suggested by Arctur and Zeiler (2004).

237 Seven thematic layers were identified early in the design of the PEI GDB. Each 238 thematic layer is a collection of geographic elements. This partition of geographic 239 information into logical information layers is a key feature for map overlay and data 240 analysis in geographical information systems (GIS) projects. The temporal resolution 241 and spatial representation of the measurements collected for this study are 242 summarized in Table 1. The advantage of the PEI GDB is that it allowed different 243 types of analysis, such as selecting particular time series or showing the evolution of 244 different variables. For the purpose of the analysis presented here, time series were 245 grouped into broad but descriptive categories so events could be classified 246 according to their general characteristics. For example, note that wind 247 measurements were stored with their original temporal resolution (2 min) in the PEI 248 GDB but were averaged to obtain hourly mean values for the purpose of the analysis 249 presented here (Section 3.2). The results presented in this paper cover nine months 250 of data collection from September 2007 to May 2008. 
252 Table 1. Time series of factors stored in the PEI GDB.

\begin{tabular}{|c|c|c|c|c|}
\hline $\begin{array}{l}\text { RAW } \\
\text { data }\end{array}$ & Used for & $\begin{array}{l}\text { Temporal } \\
\text { resolution }\end{array}$ & $\begin{array}{l}\text { Spatial } \\
\text { representation }\end{array}$ & Thematic layer \\
\hline \multirow{6}{*}{$\begin{array}{l}\text { RGB } \\
\text { images }\end{array}$} & Rectified images & $1 \mathrm{~h}$ & Raster & \multirow{3}{*}{$\begin{array}{l}\text { Surface } \\
\text { characteristics }\end{array}$} \\
\hline & Moisture maps & $1 \mathrm{~h}$ & Raster & \\
\hline & Snow-ice cover & $1 \mathrm{~h}$ & Tabular data & \\
\hline & Shoreline position & $1 \mathrm{~h}$ & Vector & \multirow{2}{*}{$\begin{array}{l}\text { Beach } \\
\text { boundaries }\end{array}$} \\
\hline & Vegetation cover & $1 \mathrm{~h}$ & Raster & \\
\hline & $\begin{array}{l}\text { Transport } \\
\text { intensity(qualitative) }\end{array}$ & $2 \mathrm{~h}$ & Tabular data & \multirow[t]{4}{*}{$\begin{array}{l}\text { Transport } \\
\text { measurements }\end{array}$} \\
\hline ED pins & $\begin{array}{l}\text { Erosion/deposition } \\
\text { processes }\end{array}$ & $1 \mathrm{~h}$ & Tabular data & \\
\hline Safires & Transport Intensity & $2 \min$ & Tabular data & \\
\hline $\begin{array}{l}\text { Beframe } \\
\text { posts }\end{array}$ & Net deposition & 2 months & Tabular data & \\
\hline \multirow[t]{2}{*}{ 2D sonic } & Wind speed & $2 \min$ & Tabular data & \multirow{2}{*}{$\begin{array}{l}\text { Wind } \\
\text { measurements }\end{array}$} \\
\hline & Wind direction & $2 \min$ & Tabular data & \\
\hline
\end{tabular}

254 3.2. Analysis of wind and transport events

255 A key element of the analysis presented here is the distinction between wind events 256 and transport events. A wind event is defined as a period of time when wind speeds 257 exceed a pre-defined threshold and thus the potential exists for aeolian sediment 258 transport to occur (Section 3.2.1). A transport event is defined as a wind event during 259 which sediment transport on the beach is measured and/or observed in photographs 260 taken by the cameras (Section 3.2.2).

262 3.2.1. Wind events

263 The threshold wind speed used to define a wind event was chosen so as to isolate 264 those periods when there was the potential for sediment transport to occur, based on 265 wind speed alone, and to ignore the rest of the record when it was unlikely that 266 transport would occur. Previous experiments by Delgado-Fernandez and Davidson- 
267 Arnott (2009) at Greenwich suggested the use of $6 \mathrm{~m} \mathrm{~s}^{-1}$ as a threshold value. The

268 minimum duration for a wind event to be considered relevant to transport was at

269 least $2 \mathrm{~h}$ over the threshold of movement. A summary of the analysis carried out to

270 determine the threshold wind speed and the minimum duration of wind event is given

271 in the appendix.

272 Events were initially grouped into 7 classes based on the mean wind speed,

273 following a classification adapted from the Beaufort scale (Table 2). The first class,

274 light breeze, contained all winds below the threshold while the remaining six classes

275 ranged from moderate breeze $\left(6-8 \mathrm{~m} \mathrm{~s}^{-1}\right)$ to fresh gale with winds $>16 \mathrm{~m} \mathrm{~s}^{-1}$.

276 Several statistics were calculated for every wind event, such as event duration,

277 mean angle of wind approach and range of wind directions.

278

279 Table 2. Wind classification used to group events based on the mean wind speed.

280 Note that the Beaufort scale goes up to 12 (hurricanes have wind speeds $\left.281>33 \mathrm{~m} \mathrm{~s}^{-1}\right)$.

282

Beaufort

\begin{tabular}{|c|c|c|c|c|}
\hline Group & $\begin{array}{l}\text { Speed } \\
\left(\mathrm{m} \mathrm{s}^{-1}\right)\end{array}$ & $\begin{array}{l}\text { International } \\
\text { description }\end{array}$ & $\begin{array}{l}\text { Speed } \\
\left(\mathrm{m} \mathrm{s}^{-1}\right)\end{array}$ & Description \\
\hline 0 & 0.3 & Calm & \multirow[t]{4}{*}{$<6$} & \multirow[t]{4}{*}{ Light breeze } \\
\hline 1 & $0.3-1.5$ & Light air & & \\
\hline 2 & $1.5-3.3$ & Light breeze & & \\
\hline 3 & $3.3-5.5$ & Gentle breeze & & \\
\hline 4 & $5.5-8$ & Moderate breeze & $6-8$ & Moderate breeze \\
\hline 5 & $8-11$ & Fresh breeze & $8-10$ & Fresh breeze \\
\hline \multirow[t]{2}{*}{6} & $11-14$ & Strong breeze & $10-12$ & Strong breeze \\
\hline & & & $12-14$ & $\begin{array}{l}\text { Very strong } \\
\text { breeze }\end{array}$ \\
\hline 7 & $14-17$ & Moderate gale & $14-16$ & Gale \\
\hline 8 & $17-20$ & Fresh gale & $>16$ & Fresh gale \\
\hline
\end{tabular}


284 The magnitude of wind events was assessed through calculation of the potential sediment transport using hourly records of mean wind speed and the duration of the wind event. In effect, this provides a measure of the potential sediment transport 287 assuming transport-limited conditions and is thus the starting point for prediction of 288 sediment supply to the foredune. The relationship proposed by Hsu (1974) was 289 adopted because of its simplicity and easy application using hourly wind speed 290 rather than bed shear velocity $\left(U^{*}\right)$ :

291

$292 q=1.16 \times{ }^{10-5} \cdot U^{3}$ equation (1)

293

294 where $\mathrm{U}$ is the mean wind speed in $\mathrm{m} \mathrm{s}^{-1}$ and $\mathrm{q}$ is the instantaneous transport rate 295 in $\mathrm{kg} \mathrm{m}^{-1} \mathrm{~s}^{-1}$. The value of q represents the potential of wind to transport sediment 296 in the direction of the wind vector. In order to obtain a magnitude based on the 297 potential of wind to deliver sediment towards the foredune, q was modified by the 298 angle of wind approach ( $\alpha$ ) relative to shore normal ( Davidson-Arnott and Law, 2991996 and Bauer and Davidson-Arnott, 2003):

300

$301 \quad q_{n}=q \cdot \cos \alpha$ equation (2)

302

303 where qn represents the potential transport into the foredune per unit alongshore 304 distance $\left(\mathrm{kg} \mathrm{m}^{-1} \mathrm{~s}^{-1}\right)$. Total sediment transport for a wind event (Q) can thus be 305 predicted by summing the potential transport for each hour: 306

$307 Q=\sum_{i=1}^{N} q_{i} \cdot 3600$ equation (3) 
310 where qi is the predicted instantaneous sediment transport rate for hour $\mathrm{i}$ and $\mathrm{N}$ is

311 the total number of hours in the event. As is the case for instantaneous transport, the

312 proportion directed towards the foredune (Qn) may be calculated as:

313

$314 Q=\sum_{i=1}^{N} q_{i} \cdot \cos \propto \cdot 3600 \quad$ equation (4)

316 Wind events were grouped into five classes ranging from very small to very large 317 potential transport based on the criteria outlined in Table 3 for both $\mathrm{Q}$ and $\mathrm{Qn}$. It is 318 worth noting that the absolute value for sediment transport predicted by

319 Eq. (1) depends in part on the constant which Hsu developed for the beaches he 320 worked on. According toSherman et al. (1998), Hsu's equation calculates transport 321 rates close to those predicted by Bagnold's (1941) equation which are in the middle 322 range respect to other equations commonly used in aeolian geomorphology.

323 Furthermore, the focus of this study was on the relative magnitude of predicted 324 transport which is controlled primarily by $\mathrm{U}^{3}$ and the duration of the event. Most 325 models use a cubic relationship between sediment transport rate and wind speed or 326 shear velocity, and in this regard, the approach was consistent with normal practice.

328 Table 3. Classification used to group events of different magnitudes based on the 329 potential to transport sediment in the direction of the wind vector $(\mathrm{Q})$ or towards the 330 dune (Qn).
Q or Qn $\left(10^{2} \mathrm{~kg} \mathrm{~m}^{-1}\right)$
Magnitude
$<3$ Very small
3-9
Small 
Q or $\mathrm{Qn}\left(10^{2} \mathrm{~kg} \mathrm{~m}^{-1}\right)$

9-27

$27-81$

$>81$
Magnitude

Medium

Large

Very large

332 3.2.2. Transport events

333 Measuring sediment transport rates is a challenging task at the meso-scale.

334 Instrumentation needs to be deployed at the beach and left unattended over long 335 periods of time. There are a number of shortcomings associated with different types

336 of deployment, such as instrument failure or periods of low quality data (e.g., ED pins

337 may be removed by waves or Safires buried by sediment accumulation). However,

338 until alternative ways of measuring actual transport rates at the beach over the time

339 frame of months are developed, available instrumentation designed for short-term 340 experiments needed to be adapted. The approach at Greenwich to overcome these

341 adversities consisted of combining the techniques described in Section 3.1 (Table 1):

342 (1) Direct measurement of saltation intensity using Safires permanently deployed at

343 the back beach and embryo dune; (2) Indirect measurement of saltation intensity

344 using RGB image interpretation. Two consecutive snapshots were necessary to 345 observe sediment movement at the beach, shown by the migration of bedforms or 346 dry sand patches. For each event, information was extracted from the offshore-,

347 west-, and east-facing cameras, and compared amongst each other; (3)

348 measurement of erosion or deposition at a point on an hourly basis using the ED

349 pins; and (4) measurement of deposition in the embryo dune/foredune every

3502 months along two survey lines using the bedframe technique.

351 In order to integrate this diverse information a qualitative scale was developed, 352 based primarily on the hourly photographic record, describing the intensity of 353 transport at the beach (Table 4). This classified transport into 6 codes ranging from 0 
354 for no transport observed or measured, to 5 with large quantities of sand being

355 transported across the entire beach. Events were associated with a transport code

356 that reflected the peak of transport intensity (in any direction) observed during the

357 event, together with the number of hours when transport was observed. In order to

358 obtain a qualitative approximation of how much sand was moved towards the

359 foredune, the transport code identified in Table 3was modified by $\cos \alpha$ to produce

360 a coden which is equivalent to qn predicted by Eq. (2). Thus for example, a code 4

361 condition with strong transport on the beach could be reduced to a coden 1 for highly

362 oblique winds.

363

364 Table 4. Criteria used to classify transport events into different classes of transport 365 intensity.
Transport
code
Description
$0-$ No
transport
1 - Trace Small gusts generating some traces of transport. Safires may or may not record transport, ED pins show no change. Subtle movement, just over threshold.
2 - Visible streamers limited to a small portion of the beach, generally
Isolated close to the shoreline. Small intensity transport, highly intermittent in Safires.
3- $\quad$ Medium intensity transport. Streamers generalized to more than one
Medium section of the beach. May be some bedform migration of a few centimetres. ED pins may record small changes.
4 - Strong Streamers generalized over entire beach. Visible bedform migration of more than $0.5 \mathrm{~m}$. Strong transport; "stormy weather" to the eye. Continuous records in Safires, and changes of two to few $\mathrm{cm}$ in ED pins.
5 - Large Overall beach modification due to aeolian processes. Major deposition scale at embryo dune/dune toe area. Largest changes of tens of $\mathrm{cm}$ in ED pins. Vegetation burial. 
3.3. Supply-limiting conditions and fetch distances

368 Moisture maps were stored with a $0.05 \mathrm{~m}$ spatial resolution. Moisture content exhibited very complicated patterns and its relation to sediment transport and wind is worthy of detailed investigation beyond the scope of this paper. For the purpose of

371 the analysis reported here the spatial distribution of moisture values was simplified 372 into three broad categories: 1) 'dry', with at least $90 \%$ of beach surface containing $373 \leq 2 \%$ of moisture; 2 ) 'threshold-changing', with moisture of $2-10 \%$ covering the 374 beach surface; and 3) 'wet', when transport was completely shut down because of 375 rainfall or melting of snow/ice (moisture $>10 \%$ over the entire beach). The goal was 376 to differentiate clearly between moments when large values for moisture content 377 ('wet') yielded no transport (Davidson-Arnott et al., 2008) while acknowledging that 378 with smaller values of surface moisture ('threshold-changing') wind gusts and drying 379 may create a diversity of transport situations (Wiggs et al., 2004 and Davidson-Arnott 380 and Bauer, 2009).

381 Percentages of snow/ice cover were calculated from rectified RGB images. A mean 382 value was obtained for each event and used for the classification outlined in Table 5. 383 This relatively simple classification permitted isolation of periods of time when the 384 beach was significantly covered by snow/ice (> 60\%). An average fetch distance was calculated for each event, given relatively constant conditions on beach dimensions 386 (e.g., frozen shoreline) and angle of wind approach. Hourly details were included in 387 the analysis when strong variations of wind direction or shoreline position resulted in 388 significantly varying fetch distances.

390 Table 5. Classification of snow/ice cover.

$\begin{array}{ll}\text { Snow-ice cover } & \text { Class } \\ \text { Complete } & >80 \%\end{array}$




\begin{tabular}{ll} 
Snow-ice cover & Class \\
\hline High & $60-80 \%$ \\
\hline Medium & $40-60 \%$ \\
\hline Low & $20-40 \%$ \\
\hline "Patches" & $<20 \%$
\end{tabular}

391

\section{Magnitude and frequency of wind events}

393

394 4.1. Wind events and potential transport in all directions

395 A total of 184 wind events were detected from September 1, 2007 to May 31, 2008 396 (Fig. 3). These encompass all the potential sediment transport events and thus the 397 starting point for prediction of sediment transport to the foredune. As expected 398 (e.g.Mathew, 2006) the frequency of events decreased with increasing values of the 399 mean wind speed class (Fig. 3A). Approximately half of wind events were 'moderate 400 breezes' with mean wind speeds of $6-8 \mathrm{~m} \mathrm{~s}^{-1}, 30 \%$ were 'fresh breezes' and $13.5 \%$ 401 were 'strong breezes'. The remaining 10 events ranged from 'very strong breezes' (6 402 events) to a single 'fresh gale' with a mean wind speed exceeding $16 \mathrm{~m} \mathrm{~s}^{-1}$. In 403 general event duration was greater with increasing mean wind speed (Fig. 3A, bar 404 graph) with most of the highest mean wind speed events lasting more than $24 \mathrm{~h}$. 405 Because of the direct relationship between event duration and mean wind speed, 406 and the fact that aeolian sand transport scales with $\mathrm{U}^{3}$ rather than $\mathrm{U}$, the mean wind 407 speed did not provide a good measure of the magnitude of the event. The potential 408 transport associated with each wind event was calculated using Eqs. (3) and (4) and 409 this value was used as a measure of the magnitude of the event for total transport 410 and for the proportion directed towards the foredune respectively (Section 3). Fig. 3B 411 shows the frequency of wind events by magnitude class as defined 412 in Table 3. Table 6 contains the relation between events magnitudes and mean wind 
413 speeds. Approximately 60\% (109 events) of all wind events fell into the very small

414 magnitude class $\left(\mathrm{Q}<3 \square 10^{2} \mathrm{~kg} \mathrm{~m}^{-1}\right)$ as a result of short durations and/or very low

415 wind speeds (83\% of events of very small magnitude were moderate breezes).

416 There were 11 large magnitude wind events $\left(27 \leq \mathrm{Q}<81 \square 10^{2} \mathrm{~kg} \mathrm{~m}^{-1}\right)$ and 4 very

417 large magnitude wind events with the potential to transport more than

$418 \quad 8.1 \square 10^{3} \mathrm{~kg} \mathrm{~m}^{-1}$.

419

420 Table 6. Percentages of wind event magnitudes (Q, Eq. (3)) in relation with mean

421 wind speeds.

Event magnitude (Q)

\begin{tabular}{|c|c|c|c|c|c|}
\hline \multirow[b]{2}{*}{ Mean wind speed $\left(\mathrm{m} \mathrm{s}^{-1}\right)$} & \\
\hline & Very small & Small & Medium & Large & Very large \\
\hline $6-8$ & $83 \%$ & $12 \%$ & & & \\
\hline $8-10$ & $15 \%$ & $73 \%$ & $48 \%$ & $9 \%$ & \\
\hline $10-12$ & $2 \%$ & $12 \%$ & $52 \%$ & $45 \%$ & \\
\hline $12-14$ & & $3 \%$ & & $27 \%$ & $50 \%$ \\
\hline $14-16$ & & & & $18 \%$ & $25 \%$ \\
\hline$>16$ & & & & & $25 \%$ \\
\hline Number of events & 109 & 33 & 27 & 11 & 4 \\
\hline
\end{tabular}

422

423 The monthly distribution of all wind events is displayed in Fig. 4A. Winter was the

424 season with the highest potential sediment transport at Greenwich, followed by Fall,

425 with the lowest potential (not presented here) in the Summer. January was the

426 month with the greatest number of wind events, and December contained the

427 strongest ones. The pie graph in Fig. 4A shows the percent of sediment potentially

428 carried by events of different magnitudes (Qm\%), which may be calculated following

429 the expression suggested byWolman and Miller (1960):

430

431

$Q_{m \%}=\frac{\left(Q_{i} \times F\right)}{Q_{t o t}} \cdot 100$

equation (5) 
433 where Qi is the sediment carried by a given magnitude wind event, $F$ is the

434 frequency of a given event, and Qtot is the total sediment transport predicted over 435 the study period. Despite their lower frequency, very large magnitude wind events

436 (one in November and three in December) accounted for a quarter of the total

437 potential sediment transport over the 9 months of the study. Very low magnitude 438 events, on the other hand, were rather inefficient in terms of potential transport; 109 439 events accounted for only $8 \%$ of the total potential sediment transport. Medium and 440 high magnitude events carried $30 \%$ and $27 \%$ of the total potential transport. Because

441 event duration increased with mean wind speed, the potential to transport sediment 442 (event magnitude) during very strong breezes and gales was enhanced, which 443 increased their significance for the total predicted transport despite their lower 444 frequencies. This has implications for modelling aeolian events in coastal areas 445 (Section 7.2).

447 4.2. Wind events and potential transport toward the foredune

448 The formation of coastal dunes requires onshore winds capable of moving sediment 449 landward (Pye, 1983 and Davidson-Arnott and Law, 1990). Offshore events 450 accounted for almost half of the total events recorded at Greenwich (90 out of 184). 451 If offshore wind events are eliminated the total predicted transport decreases to $71 \%$ 452 of the original amount. As winds with an onshore component approach the beach at 453 an increasingly oblique angle, the cosine effect drastically reduces the amount of 454 sand delivered to the foredunes per unit distance alongshore (Bauer and Davidson455 Arnott, 2003). The reduction in potential transport due to the cosine effect decreased 456 the predicted amount delivered to the foredune to approximately $41 \%$ of the total 
457 potential transport. Fig. 4B displays alongshore to onshore wind events which

458 magnitude was reduced according to how much the wind direction departed from

459 onshore perpendicular (Qn). Despite an overall decrease in the number and

460 magnitude of events, the percent of sediment potentially carried by onshore wind

461 events remained essentially the same as that for all wind events (compare pie

462 graphs in Fig. 4A and B).

463

464 5. Magnitude and frequency of transport events

465

466 The previous section examined wind events and the potential sediment transport that

467 would be predicted by an analysis using standard aeolian transport formulae. This section examines only those events, defined as transport events, where actual sediment transport was observed and/or measured. It is assumed that in all other cases transport was inhibited as a result of the presence of one or more of the

471 transport-limiting factors that act to increase the threshold for sediment entrainment 472 or shelter the beach from wind action. Note that the transport events may be, indeed 473 often are, of shorter duration than the wind event within which they are embedded, or

474 they may occupy several periods within the event because of the effect of transport-

475 limiting factors during a portion of the wind event.

476

477 5.1. Transport in all directions

478 Only 66 wind events produced observed transport (Fig. 5A), 40 of which had only 479 trace movement or isolated transport (codes 1 and 2, respectively; Table 4). The 480 remaining 26 events ranged from medium to very strong transport, and these may 481 have significant geomorphological and sediment budget implications. 
482 There was only one very strong transport event resulting from a very large

483 magnitude wind event (mean speed of 12-14 $\mathrm{m} \mathrm{s}^{-1}$, duration $90 \mathrm{~h}$ ) starting on

484 November 9 (discussed in detail in Section 6.2). There were 6 strong and 18 medium 485 transport events, which were primarily associated with medium and large magnitude 486 wind events (mean wind speeds between 8 and $12 \mathrm{~m} \mathrm{~s}^{-1}$; Table 6). Only 2 out of 18 487 medium transport events resulted from wind events with mean speeds $<8 \mathrm{~m} \mathrm{~s}^{-1}$.

488 The first occurred on March 26, 2008 with constant alongshore winds of

$4897.25 \mathrm{~m} \mathrm{~s}^{-1}$ blowing over $24 \mathrm{~h}$; the second developed on April 30, with offshore winds 490 of $7.8 \mathrm{~m} \mathrm{~s}^{-1}$ blowing dry sand from the dune and blowouts to the beach.

491 The number of hours over which transport was observed increased with the transport 492 code. Fig. 5B shows that transport events with lower codes (trace and low transport) 493 tended to last $5 \mathrm{~h}$ or less, while the mean duration of strong and very strong 494 transport events was over $25 \mathrm{~h}$ (note that there was only 1 very strong transport 495 event). The Fall was the most active season for aeolian sediment transport (Fig. 5C). 496 November contained the only event coded as 5 (very strong transport) and the 497 majority of code 4 (strong transport) events. Very few transport events were 498 recorded in the winter months of December, January and February, but transport 499 events became more frequent early in the spring and continued through 500 May. Section 6 compares transport events in Fig. $5 \mathrm{C}$ with wind events in Fig. $4 \mathrm{~A}$ and 501 examines the effects of supply-limiting factors.

502 In order to obtain an approximation of the relative proportion of sand moved by 503 transport events of different magnitude, a simple calculation multiplying the transport 504 intensity code by the duration of transport event was computed (Fig. 5D) and the 505 procedure described in Section 4.1 was applied. It is assumed here that the transport 506 classes are exponential rather than linear to account for the relationship with $U^{3}$. In 
507 other words, the increase in transport is larger when going from medium to strong

508 than from trace to low. Almost $40 \%$ of the total sediment was carried during medium

509 transport events (of medium frequency and duration according to Fig. $5 \mathrm{~A}$ and B).

510 Approximately $33 \%$ of the sediment was moved during strong transport events of low

511 frequency, followed in percentage by low intensity but frequent events (17\%) and a

512 single very strong transport event (8\%). Very small (trace) transport events were

513 insignificant in terms of the amount of sediment they carried (2.5\%). Thus, medium

514 and strong transport events were most important from the perspective of aeolian

515 sediment movement at Greenwich but how much of this sediment played a role in

516 building the foredune? What controls beach and dune sediment exchange and sand

517 input to the foredune?

518

519 5.2. Transport toward the foredune

520 Fig. 6 shows the transport events according to the predominant wind direction during

521 the event. Note that there was almost no transport associated with wind directions

522 alongshore from the east, and that the majority of transport was developed during

523 westerly winds. Most transport periods coded as 4 (strong) were associated with

524 alongshore and offshore wind angles. Alongshore winds blowing over long fetch

525 distances along the beach were able to accumulate and build-up dry sand patches

526 quickly even in the presence of high surficial moisture content. These sand bedforms

527 progressively migrated over the moist surface, 'sliding' over the beach. Fig. 7 shows

528 two examples of typical alongshore wind events with strong transport and sediment

529 moving over a moist or a frozen surface. Topographic steering might result in some

530 sediment going into the foredune with alongshore or even offshore winds (Lynch et

531 al., 2008). However, the existence and strength of recirculating eddies producing 
532 onshore transport during offshore winds still needs to be explored and is likely

533 related to factors such as dune height, wind direction, and wind speed. In agreement

534 with previous observations at Greenwich (Walker et al., 2006) the net quantity

535 delivered to the dune during offshore flows was found to be insignificant compared to

536 the total transport during the event.

537 In order to obtain an approximation of the amount of sand actually delivered to the 538 foredune the coden was calculated as explained in Section 3.2.2. Out of a total of 66 539 events, 32 had a negative qn and visible offshore transport and 7 were alongshore 540 withqn $\approx 0$; thus they have been excluded from the following analysis. Fig. 8A shows

541 the remaining 27 transport events with a coden $>0$, thus indicating that some

542 proportion of the sediment transport was directed towards the foredune. Sediment

543 input to the foredune represented approximately $27 \%$ of the total observed transport.

544 Interestingly, the only very strong transport event (code $=5$ ) occurred during oblique

545 onshore winds and thus a large proportion of sediment moved toward the foredune

546 (coden = 5). However, there were no coden $=4$ transport events and only 2 medium

547 (coden $=3)$ and 5 low $($ coden $=2)$ were identified. The remaining 19 onshore events

548 were associated with trace amounts of sediment movement (coden $=1)$. Three

549 events were responsible for approximately $75 \%$ of the total sediment input to the

550 foredune (Fig. 8C). These occurred on November 11, March 17 and May 10

551 (Fig. 8B) and their characteristics are listed inTable 7. Numerical values for these

552 three events need to be compared with actual deposition on the dune to allow a 553 proper quantification of their significance. However, in general terms, the isolation of 554 the type of events likely contributing to foredune building has important implications 555 both for what needs to be considered and what needs to be excluded for future 556 modelling (Section 7). 


\section{6. The role of limiting factors}

559

560 The comparison between applied stress (wind events) and transport processes

561 observed at Greenwich leads to several questions. The first question is why so many

562 of the observed wind events did not result in any transport, despite having the

563 potential to do so based on theoretical considerations. In particular, there is a need

564 to assess the conditions regulating the strongest wind events at the beach because

565 of their extraordinary potential to move large amounts of sediment

566 (> $27 \square 10^{2} \mathrm{~kg} \mathrm{~m}^{-1}$ per event). The windiest season (Winter) is the least effective

567 season for transport (compare Fig. 4A and B with Fig. 5 and Fig. 8, respectively).

568 While extensive snow/ice cover was responsible for preventing many transport

569 events during the winter, the comparison between Fig. 4 and Fig. 8 suggests that

570 there were other factors limiting the development of transport over the entire study

571 period. There is a need to clearly identify the role of fetch distances and moisture

572 content, and in what type of situations they play a significant role in shutting down

573 sediment transport.

574 The second question is what are the key factors limiting the development of strong

575 transport (coden $=4)$ toward the dunes at Greenwich. The comparison

576 of Fig. 5 and Fig. 8suggests that the angle of wind approach introduces a significant

577 limitation but there is a need to specify in what situations this is the primary control.

578 Finally, there is a need to clarify the characteristics surrounding the only very strong

579 onshore transport event because of its significance over the study period (29\% of

580 total sediment input to the foredune, Fig. 8C). 
581 The following sections deal with the role of limiting factors in preventing transport

582 over entire wind events (Section 6.1), decreasing the portion of time over which

583 sediment movement occurs (duration of transport event) and reducing the magnitude

584 of transport when it develops (Section 6.2).

585

586 6.1. Inhibition of sediment transport during wind events

587 About 65\% (119) of all wind events did not produce any transport (Fig. 5A). Many of

588 these (84) were associated with very small wind event magnitudes, mostly because

589 of short duration and/or with winds just above threshold. At least a quarter were

590 moderate breezes blowing over a dry surface, pointing to the relevance of the fluid

591 entrainment threshold. Because potential sediment transport associated with these

592 wind events was small, they would not make a large contribution to the error in

593 predicting actual sediment supply to the dune. However, there were 35 wind events

594 with wind speeds clearly above the threshold $\left(>8 \mathrm{~m} \mathrm{~s}^{-1}\right)$ that did not result in any

595 transport, including 3 out of the 4 very large magnitude wind events and 7 out of 11

596 large magnitude events. Table 8summarizes the main characteristics of these 10

597 wind events, which include the only fresh gale observed at Greenwich over the

598 course of nine months (December 3), 3 gales (December 1, 12, and 15), and several

599 very strong breezes. Together these 10 events accounted for $37 \%$ of the total

600 predicted sediment transport (Q) and $45 \%$ of the total predicted sediment input to the

601 foredune $(\mathrm{Qn})$. The overall result was rather different though: not only was there no

602 sediment input from the beach to the dunes, but instead sand was eroded from the

603 foredunes because of wave scarping due to storm surge and wave run-up.

604 
605 Table 8. Characteristics of 10 large magnitude wind events resulting in no transport

606 (code $=0)$. Symbols are defined in Table 7. Snow is expressed in \% of surface

607 covered.

\begin{tabular}{|c|c|c|c|c|c|c|c|c|}
\hline Date & $U$ & $U_{\max }$ & WD & $\alpha$ & Q & Qn & Snow & Limiting factors \\
\hline $03 / 12 / 07$ & 18.4 & 30.3 & 32 & $o b E$ & 11,230 & 8259 & $>80$ & $\begin{array}{l}\text { Snow/ice; storm } \\
\text { surge and foredune } \\
\text { scarping despite } \\
\text { ice foot }\end{array}$ \\
\hline $01 / 12 / 07$ & 15.3 & 23.1 & 46 & ob W & 8354 & 5938 & 15 & $\begin{array}{l}\text { Fetch extremely } \\
\text { limited (wave run- } \\
\text { up) }\end{array}$ \\
\hline 04/10/07 & 10.2 & 14.9 & 119 & ob W & 6457 & 4491 & 0 & Rain (moisture) \\
\hline $14 / 01 / 08$ & 9.9 & 15.8 & 74 & $o b E$ & 3705 & 3160 & 20 & $\begin{array}{l}\text { Storm surge and } \\
\text { short fetch distance } \\
\text { during wind peak } \\
\text { hours (ice foot acts } \\
\text { as barrier to } \\
\text { erosion); snow } \\
\text { melting (moisture) } \\
\text { prevents transport } \\
\text { during rest of event }\end{array}$ \\
\hline 02/01/08 & 11.9 & 19.4 & 38 & ob W & 3300 & 2010 & $>80$ & Snow/ice \\
\hline 23/09/07 & 12.6 & 14.9 & 40 & $\begin{array}{l}\text { on/ob } \\
\text { W }\end{array}$ & 3666 & 1918 & 0 & $\begin{array}{l}\text { Wave run-up and } \\
\text { partial embryo } \\
\text { dune scarping } \\
\text { during onshore } \\
\text { winds (ED pin at } \\
\text { the back beach lost } \\
4 \mathrm{~cm} \text { of sand due to } \\
\text { wave action); } \\
\text { intense rain during } \\
\text { oblique winds }\end{array}$ \\
\hline $12 / 12 / 07$ & 15.2 & 23.6 & 30 & ob W & 5689 & 1440 & $>80$ & Snow/ice \\
\hline $15 / 12 / 07$ & 14.5 & 24.8 & 28 & ob W & 4622 & 1193 & $>80$ & Snow/ice \\
\hline 08/12/07 & 12.5 & 19.4 & 31 & ob W & 2993 & 555 & $>80$ & Snow/ice \\
\hline $16 / 12 / 07$ & 13.2 & 26.1 & 65 & off W & 8860 & -3066 & $>80$ & Snow/ice \\
\hline \multicolumn{5}{|c|}{ Total predicted } & 58,876 & 28,964 & & \\
\hline \multicolumn{5}{|c|}{$\begin{array}{l}\text { Percent of predicted Q or Qn in } \\
9 \text { months }\end{array}$} & $37 \%$ & $45 \%$ & & \\
\hline
\end{tabular}

609 The most important limiting factor was the presence of snow and ice over the beach 610 surface during the winter months. This factor shut down sediment transport during 6 
611 of the 10 events listed in Table 8 . Included in this group is the fresh gale on

612 December 3, 2007, with the highest potential sand transport of the study period. In

613 this instance transport would also have been shut down for a large portion of the

614 event by storm surge and wave run-up, as wave action resulted in significant erosion

615 of the embryo dune. The gales on December 12 and 15 presented similar conditions,

616 with $80-90 \%$ of the surface covered by snow/ice (Fig. 9A and B). Storm surge and

617 wave run-up were the key factor preventing sediment transport during the third gale

618 on December 1 as well as wind events on October 29, 2007 and January 14, 2008.

619 The gale lasted $46 \mathrm{~h}$ but no sediment movement was recorded despite an oblique

620 onshore wind direction from the west, because of beach inundation due to wave run-

621 up (Fig. 9C and D). Rain was a primary factor preventing sediment transport alone

622 (event on October 4, 2007) or in combination with other factors (event on September

623 23, 2007) (Table 8).

624 Snow/ice covering at least $80 \%$ of the beach surface prevented sediment movement

625 in 16 of the remaining 25 low to medium magnitude wind events for which no

626 transport was observed. Snow patches or moderate to large values of surface

627 moisture due to snow melting or rain prevented sediment entrainment in the

628 remaining 9 wind events.

629 The exclusion of offshore wind events decreased the amount of total predicted

630 sediment transport $(\mathrm{Q})$ to $71 \%$ of its original amount. The reduction in potential

631 transport due to the cosine effect for those winds with an onshore component was of

$63241 \%$ respect to the transport predicted in all directions (Qn respect Q). Limiting

633 factors preventing sediment entrainment during entire onshore wind events further

634 decreased the potential input to the foredune to $16 \%$ of the original amount.

635 Furthermore, when transport was observed, limiting factors often reduced its 
magnitude due to complex relationships between wind speed, event duration, angle

637 of wind approach and fetch distance. This will be discussed in the next section.

639 6.2. 'Time limited' and 'magnitude limited' events

640 All transport events at Greenwich were 'time limited' i.e., with transport being 641 developed only over a portion of the wind event. On average, the duration of wind 642 events was approximately $25 \mathrm{~h}$, while the average duration of transport events was 643 only $8 \mathrm{~h}$. The majority of transport events were also 'magnitude limited', i.e., the 644 magnitude of the transport event was smaller than the magnitude of the wind event 645 and generally not predictable from it. For example, none of the large magnitude wind 646 events in September (Fig. 4A) resulted in strong transport (Fig. 5C). Similarly, only 1

647 of the 6 strong transport (code $=4$ ) events resulted from a large magnitude wind 648 event. Some of this complexity can be seen in Table 7, where a complex relationship 649 between wind speed, thresholds, wind direction and limiting factors regulates 650 sediment input to the foredune within the three events.

651 In order to show some these interactions it is instructive to focus on the detailed time 652 series recorded during the only very strong transport event on November 9-13, 2007 653 (Fig. 10). This event led to burial of vegetation of the embryo dune due to deposition 654 of approximately $25 \mathrm{~cm}$ of sand. Despite of strong winds exceeding the threshold for 655 sand movement for $90 \mathrm{~h}$, transport was only recorded by the Safires on the upper 656 beach for approximately $28 \mathrm{~h}$. High surface moisture content due to rainfall 657 prevented transport during the first $20 \mathrm{~h}$ of the storm. An increase of wind speed on 658 the morning of November 10 (blowing obliquely from the NE and therefore yielding a 659 relatively long fetch distance) favoured sediment movement during the second 660 portion of the storm, though the magnitude of transport was limited due to 
661 intermittent rain. A subsequent increase of wind speed coinciding with low tide (and

662 therefore a wide beach and long fetch distance) generated intense instantaneous

663 transport on the back beach. The wind direction changed from oblique to nearly

664 shore perpendicular on the morning of November 11, producing a storm surge

665 which, coupled with a rising tide, led to inundation of the beach during the final

666 portion of the storm. This resulted in a complete shut down of the aeolian transport

667 system and partial erosion of the embryo dunes.

668 In summary, transport was only detected during $28 \mathrm{~h}$ (time limited) and its intensity 669 was reduced at least over $15 \mathrm{~h}$ (magnitude limited). Furthermore, the peak in wind 670 speed did not coincide with the peak in aeolian transport, but rather with sediment 671 output from the dune because of wave scarping. This suggests that in this system

672 the strongest stresses may not yield the greatest amount of geomorphic work. These

673 results are in-line with observations on the importance of oblique angles of wind

674 approach (long fetch distances) and their relation with increases in sediment

675 transport rates on narrow beaches (Nordstrom and Jackson, 1993 and Bauer et al., 676 2009).

677

678 7. Discussion

679

680 7.1. Characteristics of wind events delivering sediment to the foredunes

681 Three events at Greenwich accounted for approximately $75 \%$ of the total transport

682 delivered to the foredune over the 9 month study period and the remainder was

683 accounted for by a small number of events of lesser magnitude

684 (Section 5.2). Fig. 11displays transport events toward the foredune (coden) with 685 respect to wind event magnitude. For the purpose of generalizing the discussion to 
other locations, wind events blowing over a surface significantly covered by snow/ice

687 are not included (total of 48). Observed transport (continuous line) was calculated by

688 adding the total transport for all events within each of the graph bars. The total

689 transport for each event is a relative value based on the intensity transport code

690 (coden) and duration of transport event (Section 5.1). This allows for an estimation of 691 the type of wind events that were responsible for sediment input to Greenwich dunes 692 over the period.

693 Initially, as the magnitude of wind events increased so did the proportion of wind 694 events resulting in transport, and the magnitude of transport associated with them 695 (Fig. 11). For example, there were 6 out of 20 medium magnitude wind events 696 generating transport, and their intensity (coden) was generally larger compared to 697 very small wind events. As a result of this, the peak of aeolian transport (continuous 698 line) was centered between small and medium magnitude wind events generating 699 low to medium magnitude transport. Beyond this a further increase of wind event 700 magnitude was associated with a decrease in total sand transport. Only 3 out of 7 701 large magnitude wind events inputted small amounts of sediment to the dune 702 (coden $=1$; traces). This is because other environmental factors, such as short fetch 703 distances and large surface moisture content, tended to limit or shut down sand 704 transport. The pattern of decreasing transport with increasing wind magnitude is 705 complicated by the existence of a single strong transport event (solid dot in Fig. 11) 706 generated by a large magnitude wind event (November 9-13, 2007), but it is difficult 707 to assess its significance without a much longer time series to provide a statistically 708 robust analysis. This event is a reminder that, given an appropriate combination of 709 factors, such as tidal stage, increasing beach width and oblique angle of wind 710 approach, a single storm may result in the transport of large amounts of sediment. 
711 However, transport during this event was both time and magnitude limited

712 (Section 6.2). More importantly, it should be contextualized with respect to the rest of

713 large magnitude wind events, as only this one out of 9 resulted in strong transport

714 toward the foredune.

715

716 7.2. Conceptual model for aeolian sediment input to foredunes

717 Fig. 12 shows (A) the original graph by Wolman and Miller (1960) of the significance

718 of events of different frequency and magnitude associated with fluvial sediment

719 transport; (B) similar curves derived from the nine-month study at Greenwich Dunes;

720 and (C) comparison between observed wind events and resulting transport as

721 explained throughout this paper. Note that only wind events with mean wind speeds

722 above $6 \mathrm{~m} \mathrm{~s}^{-1}$ were included in the analysis at Greenwich and thus Fig. 12B and C

723 lack of information below this threshold. Both the frequency of wind events (curve b)

724 and the associated mean transport rate (curve a) at Greenwich ( Fig. 12B) followed

725 the conceptual ideas proposed by Wolman and Miller (curves b and a respectively

726 in Fig. 12A). However, the introduction of the duration of the wind event

727 (curve $\mathrm{c}$ in Fig. 12B) as a factor regulating the amount of "work" done by events of

728 different magnitude has the effect of modifying the shape of the potential transport

729 with respect to the one proposed by Wolman and Miller (compare

730 curves d in Fig. 12A and B). As explained in Section 4.1, high wind speeds seldom

731 appeared isolated but rather grouped in events of long duration, which increased the

732 potential transport associated with infrequent but large magnitude wind events. In

733 other words, the amount of "work" expected from strong breezes and gales was

734 greater not only because of the larger magnitude, but also because of the high

735 positive correlation between mean wind speed and mean duration. However, the 
actual "work" performed by most of these large magnitude wind events was

737 insignificant and this was the primary source of over-prediction of sediment input to

738 the foredune at the site.

739 Fig. 12C compares predicted and observed transport at Greenwich based on the

740 results of this study. Curve $d$ is repeated from Fig. 12B and represents the predicted

741 sediment transport in any direction, and curve e represents the predicted sediment

742 transport toward the foredunes (these are equivalent to $Q$ and $Q n$ in the pie graphs

743 of Fig. 4A and B, respectively). As discussed in Section 4.2, the predicted sediment

744 transport towards the foredune was approximately $41 \%$ of the total potential

745 transport but the percent of sediment potentially carried by different magnitude wind

746 events remained essentially the same despite introducing the cosine effect.

747 Curve fis repeated from Fig. 11 and represents observed transport at Greenwich.

748 This curve summarizes, conceptually, results discussed in Section 6: sediment input

749 to Greenwich dunes was both time and magnitude limited and decreased with

750 increasing wind magnitude because of the role imposed by limiting factors such as

751 moisture or fetch distances. Gales and very strong breezes blowing over snow-free

752 surfaces resulted in storm surge and even wave scarping (Section 6.1), and thus

753 were associated with sediment removal from the foredune rather than sediment input

754 through aeolian processes. Thus, the probability of large magnitude wind events

755 producing correspondingly large magnitude transport events decreases as the mean

756 wind speed of the event increases. While the high wind speeds associated with low

757 frequency, high magnitude events are important in calculating sediment erosion and

758 transport in desert environments and agricultural fields, these may be completely

759 counterbalanced in coastal areas by processes related to nearshore dynamics and

760 beach-dune interaction ( Psuty, 1988 and Sherman and Bauer, 1993). 
762 7.3. Implications for numerical modelling

763 Meso-scale modelling approaches based on hourly measurements of wind speed 764 and direction (e.g. Fryberger and Dean, 1979) calculate sediment transport based 765 on $U^{3}$ and thus magnify the potential of strong (and long) wind events that, in the 766 coastal zone, have a very low probability of resulting in any significant sand 767 movement. Over-prediction of sediment input to the foredune on a time-scale of a 768 year is thus likely due primarily to the inclusion of large magnitude wind events 769 during which transport either does not occur or is significantly reduced, rather than to 770 uncertainty associated with estimates of the threshold value for sand movement or 771 simplifications of sediment characteristics at the beach surface (e.g., grain size).

772 There are two primary problems in attempting prediction of sediment inputs to 773 coastal dunes over periods of weeks to years: 1) determining an appropriate set of 774 equations that incorporate complexities such as surface moisture content, beach 775 width and fetch distances; and 2) securing quantitative data on these variables for 776 input into a model at time scales of weeks to months. Although an exact prediction of 777 dune development over years may not be possible using deterministic equations, 778 such simulations could aid in our understanding of the most likely scenarios 779 (Sherman, 1995). Probabilistic approaches such as those commonly used in 780 meteorological modelling may improve meso-scale sediment transport predictions in 781 coastal areas, and measuring their quality may be more critical than measuring their 782 absolute accuracy (Sutherland et al., 2004).

783 Finally, predictions of sediment supply to the foredune at the meso-scale should be 784 based on factors that can be measured or estimated rapidly and at minimal expense 785 (Davidson-Arnott and Law, 1990). Most meteorological stations along the coast 
contain hourly data sets of wind speed and direction, precipitation (both snow and

787 rain), water levels, temperature and other variables. Additionally, beach width can be

788 predicted by combining tide data and storm surge predictions based on standard

789 meteorological data. The time series at Greenwich are currently being used to

790 determine how factors such as surficial moisture content and fetch distances may be

791 estimated in this way and to assess the reliability of such predictions.

792

793

\section{Conclusions}

794

795 Some of the scale-dependent issues hampering our ability to predict dune

796 development can be addressed with a systematic identification of key controls and

797 synoptic measurement of the processes and responses involved (Sherman, 1995).

798 By analyzing when and how transport takes place at the beach, this paper identified

799 fundamental tradeoffs between key factors regulating sediment supply to the

800 foredunes. Results from the long-term monitoring at Greenwich suggest that a large

801 portion of the total sediment flux over nine months may be carried by a few small to

802 medium wind events (8-12 $\left.\mathrm{m} \mathrm{s}^{-1}\right)$, and that the angle of wind approach and fetch

803 distance may be more important than having a very strong wind. The overall role of

804 frequent but short duration periods of moderate breezes $\left(6-8 \mathrm{~m} \mathrm{~s}^{-1}\right)$ is insignificant

805 because more than $70 \%$ were not able to transport sand. Only 1 of 15 large

806 magnitude wind events delivered large quantities of sediment to the embryo dune.

807 Furthermore, the strongest wind events did not result in aeolian transport at all but,

808 rather, yielded wave scarping and foredune erosion. The windiest season (Winter)

809 was the least important for aeolian sediment transport because of the effect of 
810 snow/ice cover on this beach. At least $60 \%$ of the largest magnitude wind events

811 encountered a surface protected by a frozen beach.

812 There are a number of methodological and conceptual limitations that this paper

813 does not consider but are of potential relevance. Topographic adjustments were not

814 quantified during wind events (and for extended periods of time) due to instrumental

815 limitations and access to the site. Also, methods to measure sediment transport over

816 long time periods require improvement. Furthermore there is a need to compare

817 qualitative observations of transport processes with actual measures of deposition at

818 the embryo dune and foredune over several months, and to incorporate the ideas

819 explained in this paper in new modelling approaches. The study site at Greenwich

820 Dunes is representative of many beaches in the Gulf of Saint Lawrence, east coast

821 of Canada and the Great Lakes. While the details of beach-dune systems in other

822 areas will be different because of different wave, tidal and climate regimes, and thus

823 result in changes in the efficiency of different magnitude wind events (e.g., skews in

824 the transport curve) the conceptual approach described here may be universally

825 applicable. Also, although the objective of this paper was to identify general patterns

826 and the role of a few key parameters future studies should explore the details of

827 many events individually (such as possible niveo-aeolian activity during two winter

828 events, sublimation processes, and relations between bedform shape and rate of

829 migration under different wind and surface conditions).

830 Finally, monitoring stations such as the one deployed at Greenwich should be

831 maintained for periods of years to assess seasonal and inter-annual variability.

832 Although key factors controlling sediment dynamics will likely vary depending on the

833 geographical location and beach dimensions, the contribution of this paper was to

834 demonstrate that the largest transport rates do not necessarily occur during periods 
835 when wind speeds are at their greatest. This is linked to the essential characteristics

836 of aeolian transport on coastal areas, which yield tradeoffs between beach geometry,

837 angle of wind approach and fetch distance. These critical interrelationships reinforce

838 the uniqueness of coastal dunes.

839

840 Acknowledgments

841

842 We thank Parks Canada for granting permission to carry out work at Greenwich

843 Dunes and personnel at Greenwich Dunes for their support in the field. Special

844 thanks to Roger Steadman and Allan Doyle for help with transporting equipment to

845 and from the research site. Financial support for the study has been provided

846 through a Natural Sciences and Engineering Research Council of Canada Discovery

847 Grant to RD-A, through a research grant from Parks Canada to RD-A, lan Walker

848 and Jeff Ollerhead, and through a University of Guelph Lattornell Travel grant to ID-

849 F. ID-F also acknowledges support provided by the Ontario Graduate Scholarship

850 Program. Jeff Ollerhead provided help with many of the aspects related to data

851 collection and monitoring. Mario Finoro and Sandy McLean provided technical

852 support for the construction of the station at Greenwich, and Adam Bonnycastle

853 aided in the development of scripts to process the data. A number of people have

854 been involved in the fieldwork and we would particularly like to thank Bernie Bauer,

855 lan Walker, Hosahng Rew, Rosie Smit, Kathryn Powel, and Gavin Manson. We

856 would like to thank the thoughtful suggestions by Bernie Bauer, which greatly

857 improved the paper, as well as detailed reviews by Bill Nickling and Ray

858 Kostaschuck. We are grateful to the feedback and comments provided by two

859 anonymous reviewers. 


\section{Appendix}

862

863 This research makes use of hourly wind speed recorded at $14 \mathrm{~m}$ height over the

864 beach surface. Thus, there is a need to justify the use of both the wind velocity and 865 the minimum velocity to keep sand in saltation at $14 \mathrm{~m}$ as a surrogate for drag 866 velocity and threshold shear velocity. According to Fryberger and Dean (1979, p.

867 146) one may use hourly wind speed data at $10 \mathrm{~m}$ height over the beach surface to 868 predict transport by making several simplifying assumptions. If shear velocity is 869 proportional to the wind velocity at any given height then the Lettau and Lettau 870 (1977) equation may be modified as follows:

871

$872 q \propto U^{* 2}\left(U^{*}-U_{t}^{*}\right)$ equation (6)

873

874 into:

875

$876 q \propto U^{2}\left(U-U_{t}\right) \cdot t$ equation (7)

877

878 where $U^{*}$ and $U^{*} t$ are the shear velocity and impact threshold shear velocity 879 respectively (Eq. (6)), $\mathrm{U}$ is wind velocity, $\mathrm{Ut}$ is the impact threshold wind velocity 880 (both at an average height of $10 \mathrm{~m}$ ) and $\mathrm{t}$ is the time wind blew (Eq. (7)). Fryberger 881 and Dean assumed that (1) the surface consists of loose quartz sand grains with an 882 average diameter $0.25-0.3 \mathrm{~mm}$; (2) the surface is dry, unvegetated and free of 883 bedforms larger than ripples, and; (3) the threshold wind velocity may be 884 extrapolated using Bagnold's equation (1941, p. 104): 
888 where $z^{\prime}$ is the roughness surface factor and $U^{\prime} t$ is the threshold wind velocity at a

889 height $z^{\prime}$. Fryberger and Dean derived the following values from work by Belly (1964)

890 for a sand surface of $0.3 \mathrm{~mm}$ average:

891

$z^{\prime}=3.05 \times 10^{-3} \mathrm{~m}$

$U_{t}^{\prime}=2.74 \mathrm{~ms}^{-1}$

$U_{\mathrm{t}}^{*}=0.16 \mathrm{~ms}^{-1}$

893

894 The resulting wind impact threshold wind velocity at Greenwich following Fryberger 895 and Dean's approach is $U \mathrm{t}(14 \mathrm{~m})=6.11 \mathrm{~m} \mathrm{~s}^{-1}$, which is similar to the one used in this study based on calculations by Delgado-Fernandez and Davidson-Arnott (2009) after

897 a short-term experiment at Greenwich beach. These authors compared mean values

898 of wind speed at $0.25 \mathrm{~m}$ and $14 \mathrm{~m}$ height over the beach surface extracted from 20

899 10-minute runs (Fig. 13) and suggested an approximate correlation factor of 0.66.

900 Previous research by Davidson-Arnott et al. (2008) involving the use of cup

901 anemometers and saltation probes at the same study site suggested a minimum

902 wind speed of $4.2 \mathrm{~m} \mathrm{~s}^{-1}$ at $0.3 \mathrm{~m}$ high for measuring transport (average value for cup

903 anemometer at the foreshore).Delgado-Fernandez and Davidson-Arnott

904 (2009) decreased this threshold to $4 \mathrm{~m} \mathrm{~s}^{-1}$ to ensure that no transport periods were 905 lost during a filtering procedure. Thus, a wind of $4 \mathrm{~m} \mathrm{~s}^{-1}$ at $0.25 \mathrm{~m}$ high corresponds 906 to $6.1 \mathrm{~m} \mathrm{~s}^{-1}$ at $14 \mathrm{~m}$.

907 Finally, Bagnold (1941, p. 101) suggests that the threshold velocity at any

908 height $z$ may be calculated as follows: 
912 where $A=0.1, \sigma$ is the density of grain material $\left(2650 \mathrm{~kg} \mathrm{~m}^{-3}\right), \rho$ is the density of air $913\left(1.22 \mathrm{~kg} \mathrm{~m}^{-3}\right), \mathrm{d}$ is the grain diameter $(0.26 \mathrm{~mm}$ at Greenwich beach), $\mathrm{k}$ is the 914 roughness factor $\left(z^{\prime}=3.05 \times 10^{-3} \mathrm{~m}\right)$, and $z=14 \mathrm{~m}$. Under these

915 conditions, $\mathrm{Ut}_{(14 \mathrm{~m})}=4.99 \mathrm{~m} \mathrm{~s}^{-1}$, which is significantly lower that the values predicted 916 previously.

917 The use of one threshold value for wind speed over months contradicts many

918 findings about the high variability of thresholds for sand movement at the

919 instantaneous scale (e.g., Wiggs et al., 2004 and Davidson-Arnott and Bauer, 2009).

920 Furthermore, any of the methods above require several assumptions regarding 921 sediment and flow characteristics, which introduce uncertainties in calculations (e.g., 922 an increment of $z^{\prime}$ from 0.0018 to 0.01 decreases $U t_{(14)}$ from 6.55 to $5.63 \mathrm{~m} \mathrm{~s}^{-1}$ in 923 Eq. (8)). Variations in sediment size and sorting, packing and surface characteristics 924 will introduce large variations in the critical shear stress and hence will have 925 significant effects on transport. However, one may assume a low enough wind 926 threshold for dry sand under which transport is not likely to occur. Sediment transport 927 rates around this threshold are also likely to be small, so the effect should be 928 insignificant in predicting total sediment transport over a period of months. Analysis 929 in this study suggest that the refinement of the wind threshold for dry sand may not 930 be a first order priority if this is used to isolate moments where transport has the 931 potential to occur (wind events). There was only one transport event of less than $9326 \mathrm{~m} \mathrm{~s}^{-1}$ over nine months at Greenwich (mean wind speed $=5.1 \mathrm{~m} \mathrm{~s}^{-1}$, duration of 933 wind event $=10 \mathrm{~h}$; transport code $=1$-traces; duration of transport $=2 \mathrm{~h}$ ). Events with 
934 wind speeds from 6 to $8 \mathrm{~m} \mathrm{~s}^{-1}$ were responsible of only $2.5 \%$ of the total transport in

935 all directions. Wind events driving the majority of sediment to the foredunes

936 presented higher wind speeds.

937 Two images were necessary to observe evidences of sediment movement from

938 bedform migration or ED pins records and thus this dictated the minimum duration of 939 an event. Isolated hourly records of wind speeds over $6 \mathrm{~m} \mathrm{~s}^{-1}$ did take place in the

940 time series but were ignored in the analysis, which was also supported by the lack of

941 transport evidences from the Safires records during those particular short time

942 periods. Even if transport may have occurred this was negligible over the long-term

943 because isolated records of wind speed tended to be of very low magnitude. There

944 were 83 isolated hourly values of wind speeds $>6 \mathrm{~m} \mathrm{~s}^{-1}$ and $78(94 \%)$ of them were $945<8 \mathrm{~m} \mathrm{~s}^{-1}$.

946

\section{References}

948

949 Arctur, D. and Zeiler, M., 2004. Designing geodatabases: case studies in GIS data 950 modeling. ESRI, Redlands, California, 393 pp.

951 Baas, A.C.W., 2007. Complex systems in aeolian geomorphology. In: Murray, A.B. 952 and Fonstand, M.A. (Eds.), Proceedings of the $38^{\text {th }}$ Binghamton Geomorphology Symposium, Duke University, October 5-7. Geomorphology $91 \mathrm{SI}, 311-331$.

955 Bauer, B.O. and Davidson-Arnott, R.G.D., 2003. A general framework for modeling 956 sediment supply to coastal dunes including wind angle, beach geometry and fetch effects. Geomorphology 49, 89-108. 
958 Bauer, B.O., Davidson-Arnott, R.G.D., Hesp, P.A., Namikas, S.L., Ollerhead, J., Walker, I.J., 2009. Aeolian sediment transport on a beach: Surface moisture, wind fetch, and mean transport. Geomorphology 105, 106-116.

961 Chapman, D.M., 1990. Aeolian sand transport - an optimized model. Earth Surface $962 \quad$ Processes and Landforms, 15, 751-760.

963 Christiansen, M.B. and Davidson-Arnott, R.G.D., 2004. Rates for landward sand 964 transport over the foredune at Skallingen, Denmark and the role of dune 965 ramps. Geografisk Tidsskrift, Danish Journal of Geography 104, 27-36.

966 Coulthard, T.J., 2009. Numerical models of catchment scale sediment transfer: 967 progress, problems and potential, Eos Trans. AGU 90, Jt. Assem. Suppl., Abstract H74B-02

Darke, I., Davidson-Arnott, R.G.D. and Ollerhead, J., 2009. Measurement of beach 970 surface moisture using surface brightness. Journal of Coastal Research 25, 248-256.

972 Davidson-Arnott, R. G. D. and Law, M. N., 1990. Seasonal patterns and controls on 973 sediment supply to coastal foredunes, Long Point, Lake Erie. In: Nordstrom, K. F., Psuty, N. P. and Carter, R. W. G., (Eds.), Coastal Dunes: Form and Processes, John Wiley \& Sons Ltd., 177-20.

977

978

Davidson-Arnott, R. G. D. and Law, M. N. 1996. Measurement and prediction of long-term sediment supply to coastal foredunes. Journal of Coastal Research

979 Davidson-Arnott, R.G.D., MacQuarrie, K. and Aagaard, T., 2005. The effect of wind 980 gusts, moisture content and fetch length on sand transport on a beach. Geomorphology 63, 115-129. 
982 Davidson-Arnott, R.G.D., Yang, Y., Ollerhead, J., Hesp, P.A. and Walker, I.J., 2008. The effects of surface moisture on aeolian sediment transport threshold and mass flux on a beach. Earth Surface Processes and Landforms 33, 55 - 74.

Davidson-Arnott, R.G.D. and Bauer, B.O., 2009. Aeolian sediment transport on a beach: Thresholds, intermittency, and high frequency variability.

987 Geomorphology 105, 117-126.

988

Delgado-Fernandez, I. and Davidson-Arnott, R.G.D., 2009. Sediment input to 989 foredunes: description and frequency of transport events at Greenwich Dunes, Prince Edward Island, Canada. Journal of Coastal Research, SI 56, Proceedings of the $10^{\text {th }}$ International Coastal Symposium, Lisbon, Portugal, 302-306, v1.

Delgado-Fernandez, I., Davidson-Arnott, R.G.D. and Ollerhead, J., 2009. Application 994 of a remote sensing technique to the study of coastal dunes. Journal of 995 Coastal Research 25, 1160-1167.

Fryberger, S. G. and Dean, D., 1979. Dune forms and wind regime. In: McKee, E. D. 997 (Ed.), A Study of Global Sand Seas. U. S. Geological Survey Professional 998 Paper 1052. Chapter F., 141-151

Hesp, P.A., Davidson-Arnott, R.G.D., Walker, I.J. and Ollerhead, J., 2005. Flow dynamics over a foredune at Prince Edward Island, Canada. Geomorphology 1001 $65,71-84$.

1002 Higgitt, D.L., and Lee, M.E., 2001. Geomorphological processes and landscape 1003 change: Britain in the last 1000 years, Wiley-Blackwell, 320 pp.

1004 Hsu, 1974. Computing eolian sand transport from routine weather data. Proceedings 1005 of the $14^{\text {th }}$ Conference on Coastal Engineering, ASCE, New York, 1619-1626. 
1006

1007

1008

1009

1010

1011

1012

1013

1014

1015

1016

1017

1018

1019

1020

1021

1022

1023

1024

1025

1026

1027

1028

1029

1030

Lynch, K., Jackson, D.W.T. and Cooper, A.G., 2008. Aeolian fetch distance and secondary airflow effects: the influence of micro-scale variables on mesoscale foredune development. Earth Surface Processes and Landforms 33, 991-1005.

Mathew, S., 2006. Wind Energy. Fundamentals, Resource Analysis and Economics, Springer, xii+246 pp.

Miot da Silva, G., Hesp, P.A., and Dillenburg, S.R. (in press). Coastline orientation, aeolian sediment transport and foredune and dunefield dynamics of Moçambique Beach, southern Brazil. Earth Surface Processes and Landforms.

Nordstrom, K.F., Jackson, N.L., Bruno, M.S. and de Butts, H.A., 2002. Municipal initiatives for managing dunes in coastal residential areas: a case study of Avalon, New Jersey, USA. Geomorphology 47, 137-152.

Ollerhead, J., Johnson, P., Davidson-Arnott, R.G.D., Walker, I. and Hesp, P.A., 2003. Sediment supply to coastal foredunes, Greenwich Dunes, Proceedings of the Canadian Coastal Conference. CCSEA, Kingston, Ontario, pp. 12.

Psuty, N.P., 2005. The Evolving Paradigm of Coastal Geomorphology Inquiry. In: Sanjaume, E. and Mateu., J. (Eds.), Geomorfologia Litoral i Quaternari, Homenatge al professor V.M. Rossello i Verger. Universitat de Valencia, Spain, 373-382.

Pye, K., 1983. Coastal Dunes. Progress in Physical Geography 7, 531-597.

Sherman, D.J., 1995. Problems of scale in the modeling and interpretation of coastal dunes. Marine Geology 124(1-4): 339-349.

Stout, J.E. and Zobeck, T.M., 1997. Intermittent saltation, Sedimentology 44, 959970. 
1031 Sutherland, J., Peet, A. H. , and Soulsby, R.L., 2004. Evaluating the performance of 1032 morphological models. Coastal Engineering 51, 917-939.

1033 Svasek, J. N. and Terwindt, J. H. J., 1974. Measurement of sand transport by wind 1034 on a natural beach, Sedimentology $21,311-322$.

1035 Walker, I.J., Hesp, P.A., Davidson-Arnott, R.G.D. and Ollerhead, J., 2003. Topographic effects on airflow over a vegetated foredune: Greenwich Dunes, Prince Edward Island, Canada. Proceedings Coastal Sediments '03. ASCE, 1038 New York, pp. 15.

1039 Walker, I. J., Hesp, P.A., Davidson-Arnott, R.G.D., and Ollerhead, J., 2006.

1040 Topographic Steering of Alongshore Airflow over a Vegetated Foredune:

1041 Greenwich Dunes, Prince Edward Island, Canada. Journal of Coastal $1042 \quad$ Research 22, 1278-1291.

1043 Wiggs, G.F.S., Atherton, R.J. and Baird, A.J., 2004. Thresholds of aeolian sand 1044 transport: establishing suitable values. Sedimentology 51, 95-108.

1045 Wolman, M.G. \& W.P Miller. 1960. Magnitude and frequency of forces in geomorphic 1046 processes. Journal of Geology 68, 54-74.

1047

1048 References Online:

10491. Environment Canada, Atlantic Climate Center 1050 http://atlantic-web1.ns.ec.gc.ca/climatecentre/default.asp?lang=En\&n=CACEE433-1 1051 [Consult : July 30, 2009]

1052

1053 List of Figures 

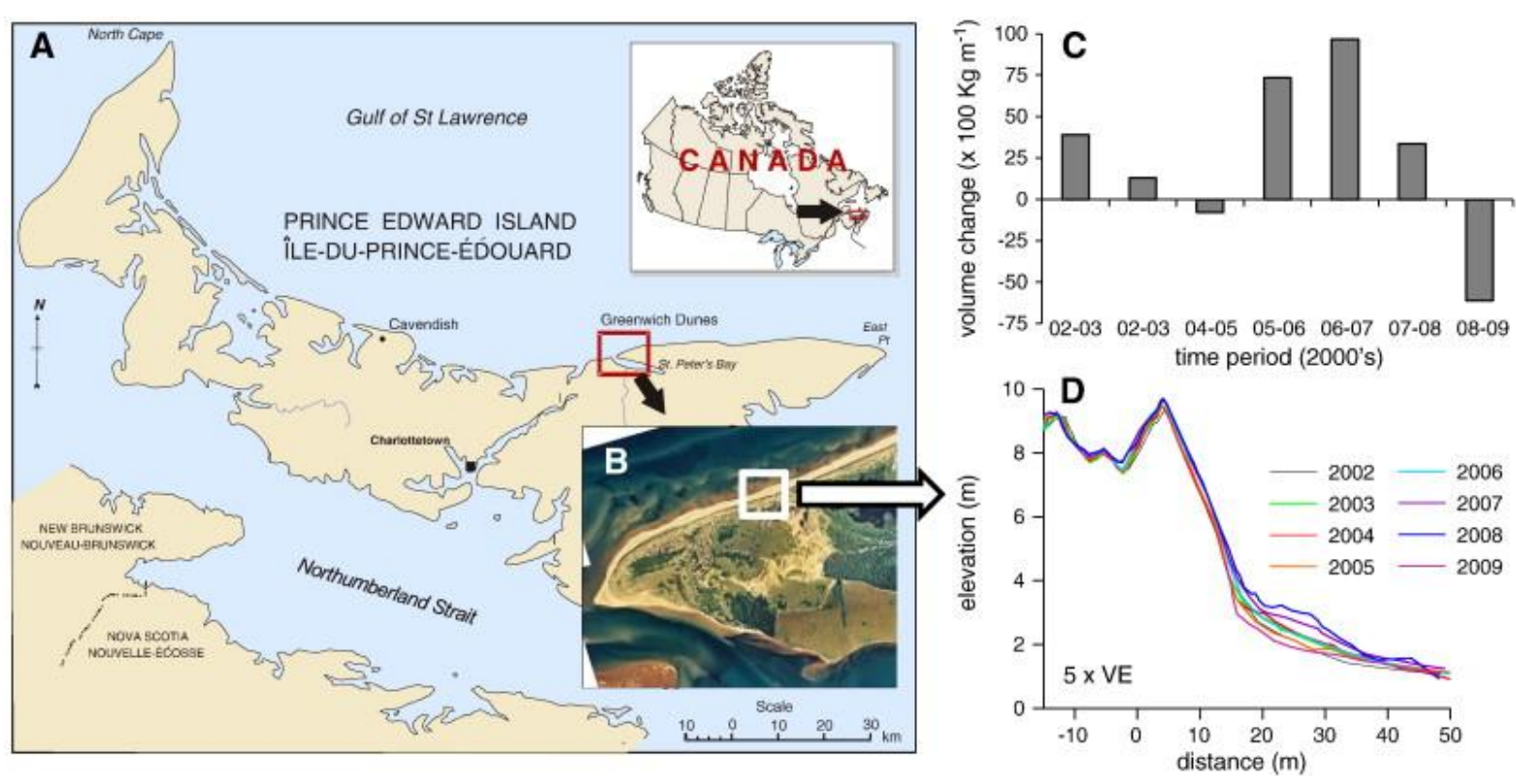

Fig. 1. A) Location of study area; B) Close up on Greenwich Dunes and location of the study site (white box); C) Net volume changes measured by the bedframe technique at line W located within the study site during the decade of the 2000s (see relative location in Fig. 2); D) DGPS surveys of line W reflecting the focus of changes occurring at the embryo dune and foredune toe.

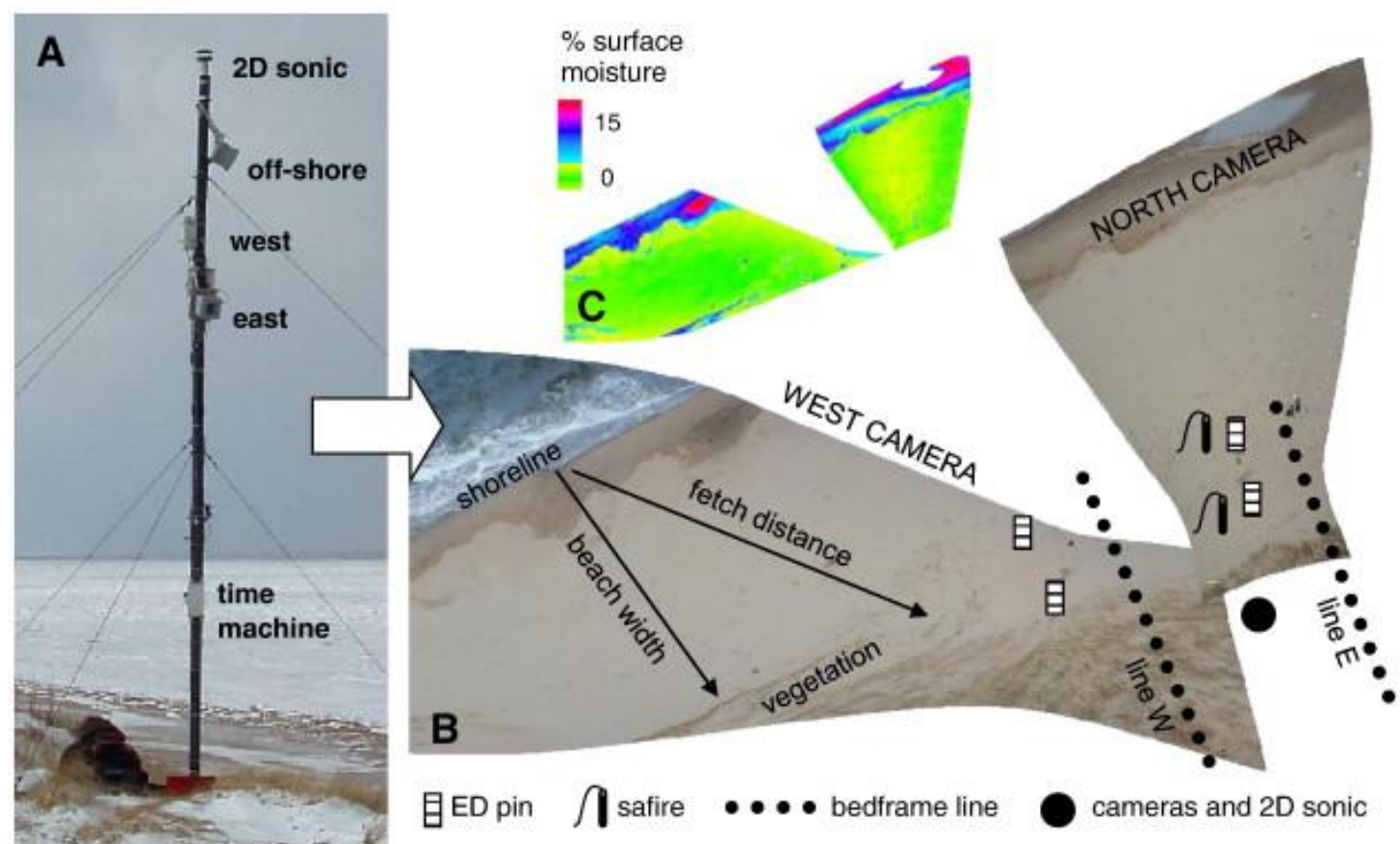


Fig. 2. A) Principal components of the long-term monitoring station. A 2-D sonic anemometer was located at the top of the mast, with three digital cameras below it; B) Example of rectified images for the offshore (north facing) and west-facing cameras and instruments deployment; C) example of moisture map produced from rectified RGB images (after Delgado-Fernandez et al., 2009).

1055

A

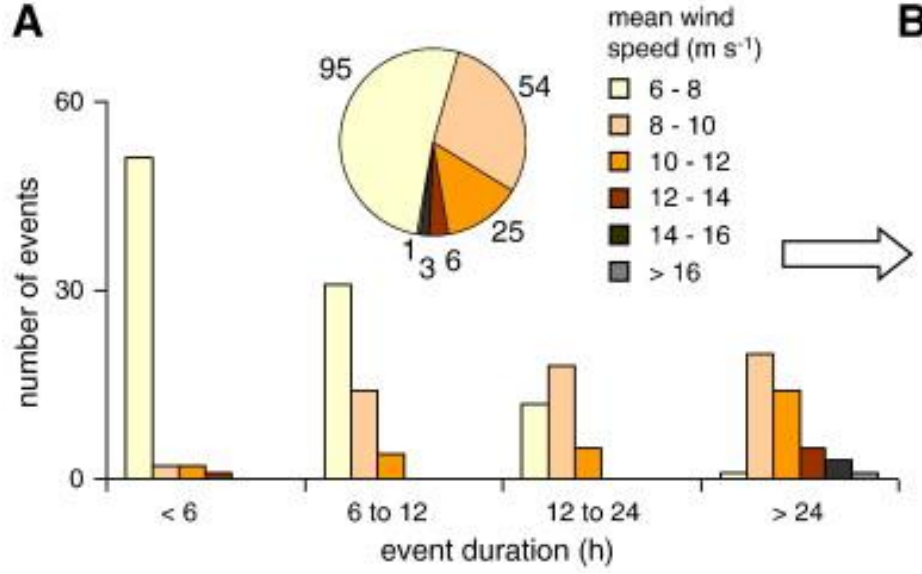

B

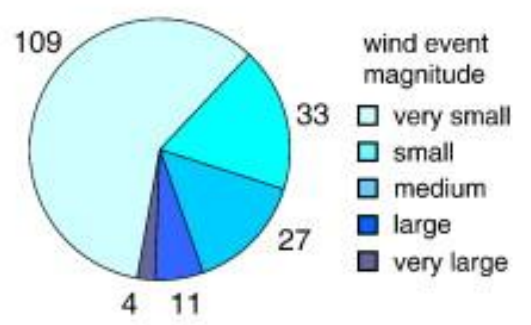

Fig. 3. A) Percentage and duration of wind events with different mean wind speeds. In general, the number of events decreased and the event duration increased with increasing mean wind speed; B) Magnitude of wind events based on potential sediment transport $\mathrm{Q}\left(\mathrm{kg} \mathrm{m}^{-1}\right)$ calculated using hourly wind speed and event duration (Eq. (3)). Table 6 contains the relation between events magnitudes and mean wind speeds. Note that $60 \%$ of all events (109) had very low magnitudes and only $2 \%$ ( 4 events) fell into the very large magnitude class. The values outside of the pie chart indicate the number of events. 

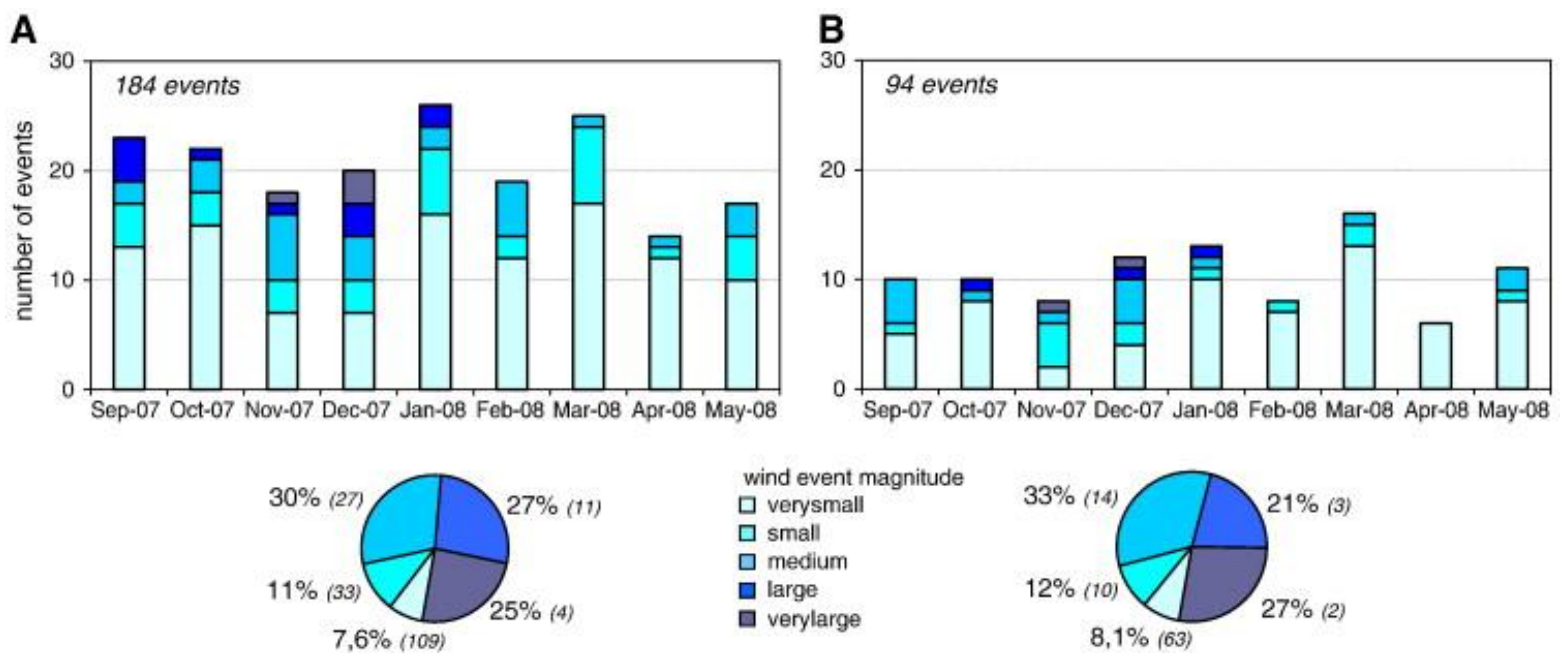

$$
\begin{aligned}
& \text { wind event } m \\
& \square \text { verysmall } \\
& \square \text { small } \\
& \square \text { medium } \\
& \square \text { large } \\
& \square \text { verylarge }
\end{aligned}
$$

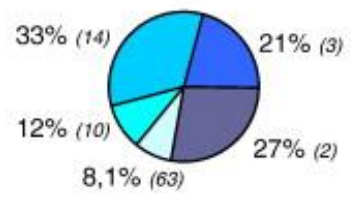

Fig. 4. A) Monthly distribution of all wind events (all directions), with magnitudes based on $\mathrm{Q}\left(\mathrm{kg} \mathrm{m}^{-1}\right)$; B) Monthly distribution of wind events potentially delivering sediment to the dune (onshore to alongshore), with magnitudes based on $\mathrm{Qn}\left(\mathrm{kg} \mathrm{m}^{-1}\right)$. Offshore events make up approximately half of the total number of wind events (90 out of 184). The exclusion of offshore events and modification of transport by the cosine of the angle of wind approach reduced the total amount of sediment potentially transported to the foredunes to $41 \%$ of the total $\mathrm{Q}$. The associated pie diagrams show the percent of potential sediment carried by events of different magnitude ( Section 4.1). The numbers outside of the pie charts indicate the percentage and corresponding number of events (in brackets). Despite the decrease in potential sediment transport toward the foredune the proportion of wind events with different magnitudes remained essentially the same. 

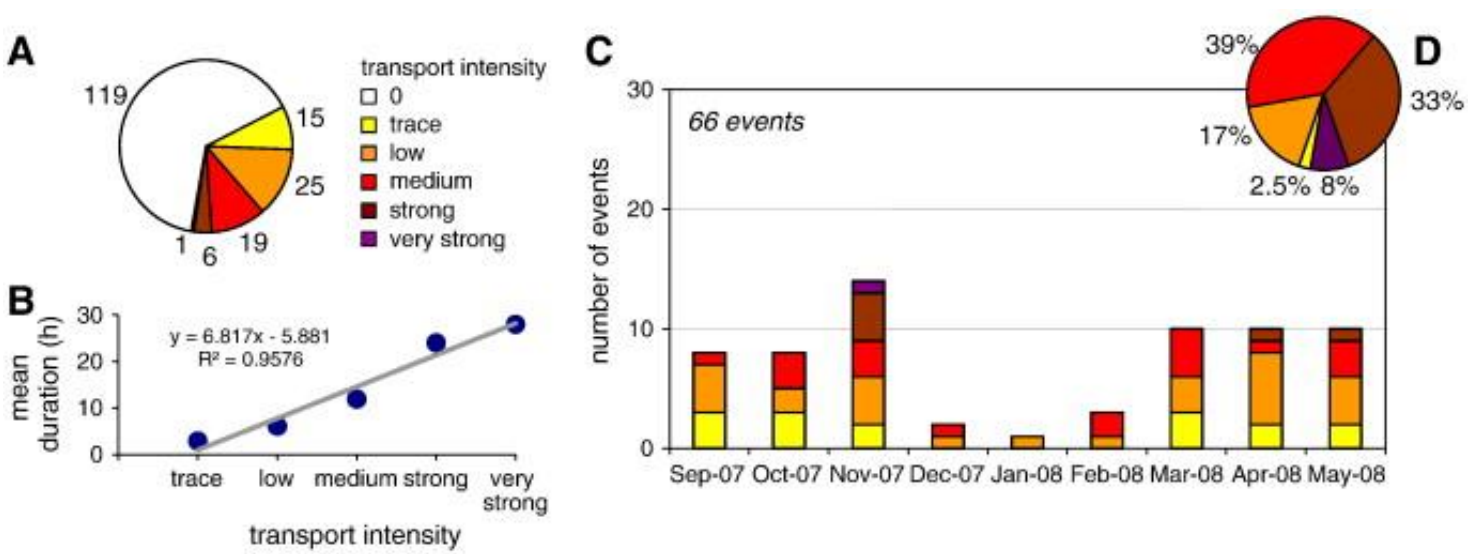

Fig. 5. Observed transport from all directions, based on the qualitative transport code assigned to each event (Table 4). A) Frequency of transport events. Values on the outside of the pie chart indicate the number of events with different transport intensities. The total number of transport events was 65; B) Relation between transport event intensity and transport event duration; C) Monthly distribution of transport events. Note that the strongest and the largest number of events occurred in November; this graph may be compared with the monthly distribution of wind events from all directions in Fig. 4A; D) Percent of total sediment carried by transport events of different magnitudes (Section 5.1). Values on the outside of the pie chart specify the actual percentage value.

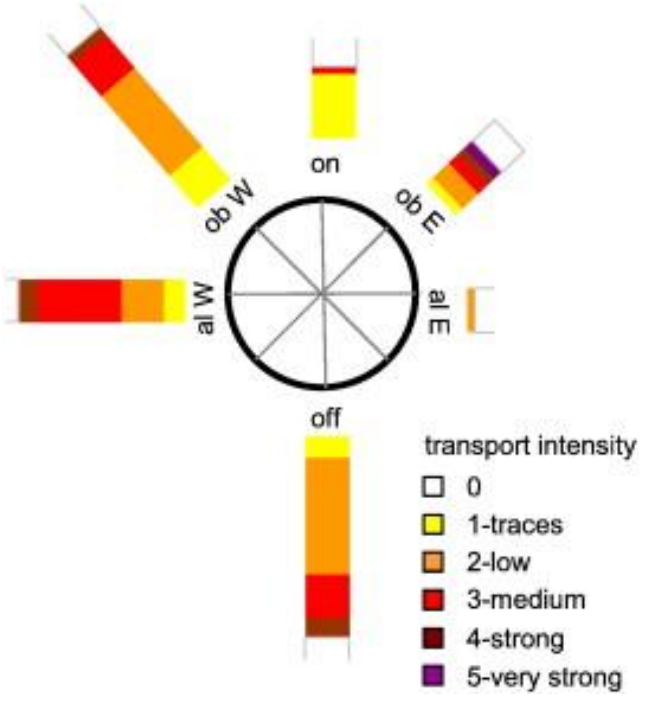


Fig. 6. Grouping of transport events at Greenwich Dunes based on the predominant wind direction for each event; "on" = onshore; "ob" = oblique; "off" = offshore. Note that a large percentage of the observed transport was associated with either offshore or alongshore wind directions which are assumed to deliver little or no sediment to the foredune.
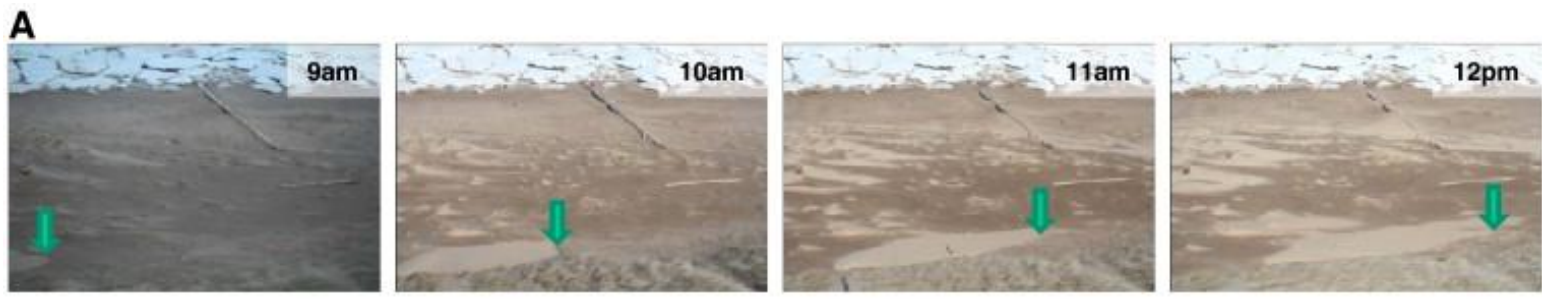

B
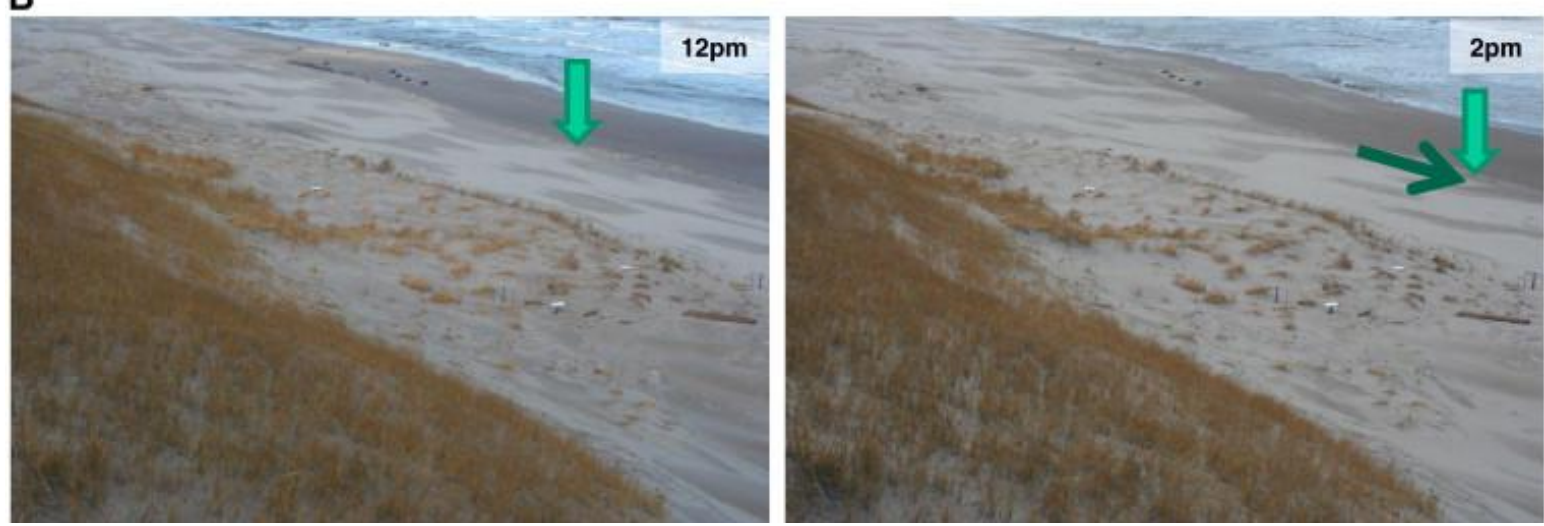

Fig. 7. A) Time series of images taken by the onshore camera during an alongshore transport event on April 3, 2008. Note that the shoreline is frozen and that dry sand transported by the wind seems to "slide" over the beach surface. The arrow points to the beginning of the sand patch as it enters into the field of view of the camera ( 9 am) and subsequently moves along the dune toe driven by the wind; B) Snapshots from the west-facing camera during an alongshore event on November 17, 2007. The first image (12 pm) was taken close to the beginning of the wind event, with patches of dry sand being formed over the wet surface. The second image was taken $2 \mathrm{~h}$ later, with alongshore sediment transport fully developed. 


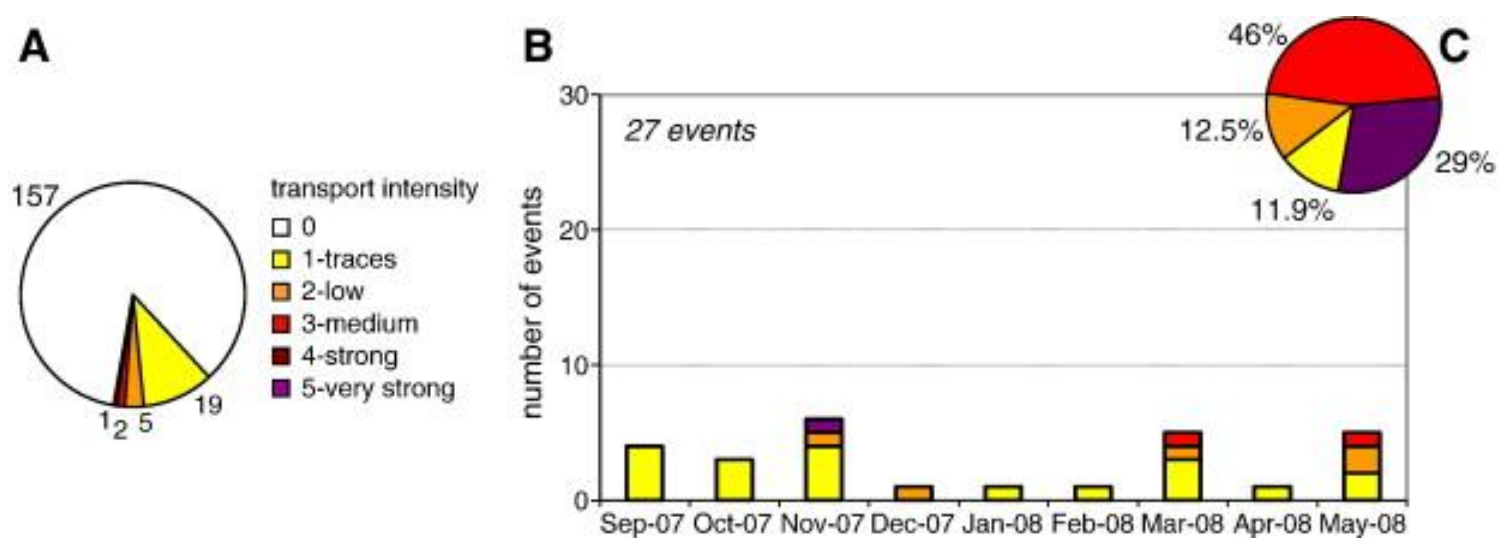

Fig. 8. Observed total transport modified by the angle of wind approach (coden Section 5.2). A) Frequency of transport events delivering sediment to the foredune. Values on the outside of the pie chart specify the absolute number of events with different transport intensities. The total number of events was 27 . Note that there were no strong transport events toward the foredunes; B) Monthly distribution of transport events toward the foredune. Note that November contained the only very strong transport event, while the two medium events occurred March and April. This graph may be compared with the monthly distribution of wind events toward the foredune in Fig. 4B; C) Percentage of total sediment carried by transport events of different magnitudes (Section 5.1). Values on the outside of the pie chart specify the actual percentage value. 

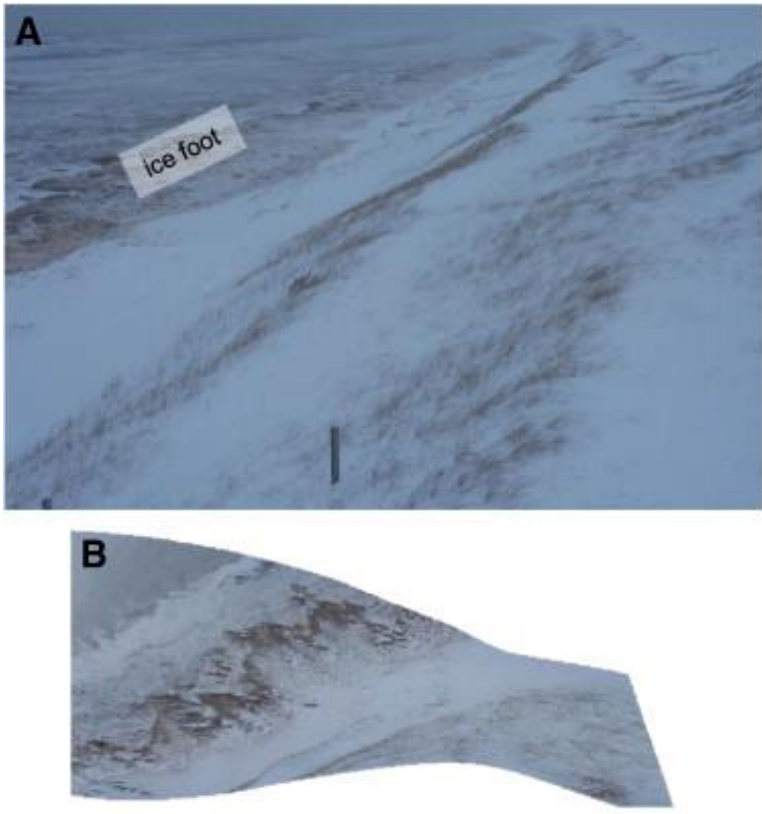


Fig. 9. Example of images taken by the east-facing camera during two large magnitude wind events at Greenwich. A) Gale on December 15, 2007: 30 h of strong winds (mean wind speed $=14.5 \mathrm{~m} \mathrm{~s}^{-1}$ ) did not produce any transport because of snow/ice cover; C) Gale on December 1, 2007: strong winds (mean wind speed $=15 \mathrm{~m} \mathrm{~s}^{-1}$ ) over $40 \mathrm{~h}$ were accompanied by extremely short fetches due to wave run-up. No transport was developed despite an oblique onshore angle of wind approach; B-D) Examples of rectified images from the west-facing camera taken at the same time/date as $\mathrm{A}$ and $\mathrm{C}$ respectively.

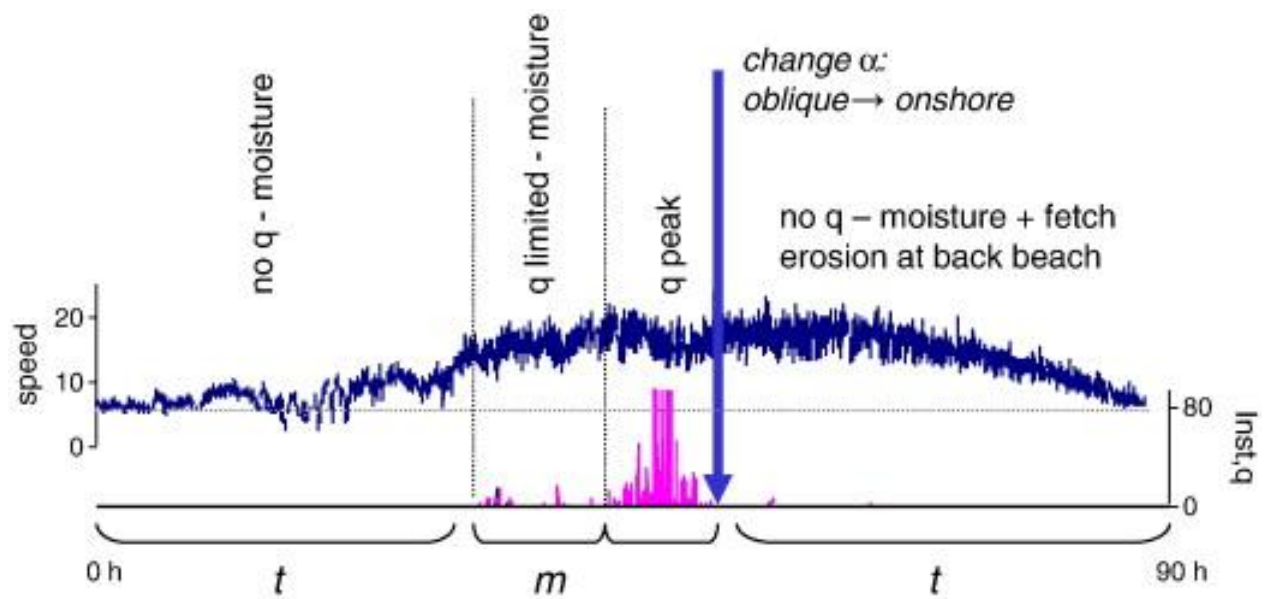


Fig. 10. Time (t) and magnitude $(\mathrm{m})$ limited event. Wind speed (upper line, scale on the left) is expressed in $\mathrm{m} \mathrm{s}^{-1}$; saltation intensity (scale on the right) refers to the number of grains per second counted by a Safire averaged over 2 min. The $x$ axis represents the time from 0 (beginning of wind event) to $90 \mathrm{~h}$ (end of wind event).

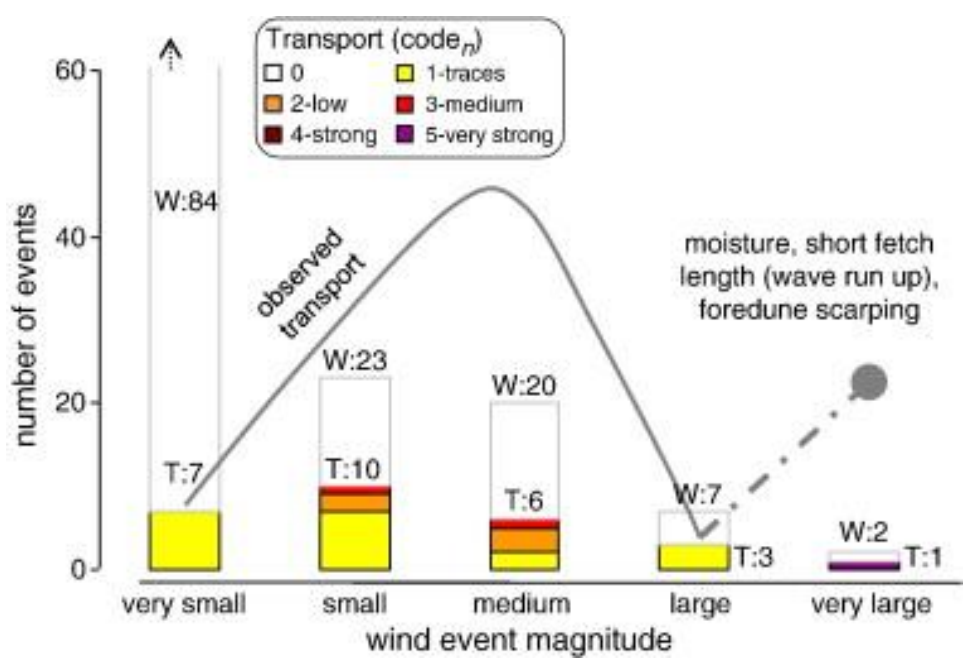

Fig. 11. Transport events (bar graph) and aeolian transport (line graph -

Section 5.1) associated with different wind event magnitudes at Greenwich. The line graph is the result of adding the calculated transport of all events within the same bar in the graph. Wind events blowing over a snowed/iced surface have been excluded. W: number of wind events; T: number of transport events. As the magnitude of wind event first increased the proportion of wind events resulting in transport (T/W) increased. The peak of aeolian transport was associated with small to medium magnitude wind events. A further increase of the magnitude of wind event did not result in an increase of transport because the presence of factors such as moisture and short fetch distances. Only 1 out of 9 large and very large wind events produced strong transport, though sediment movement during this event was both time and magnitude limited (Section 6.2) and thus lower than the theoretical maximum. 

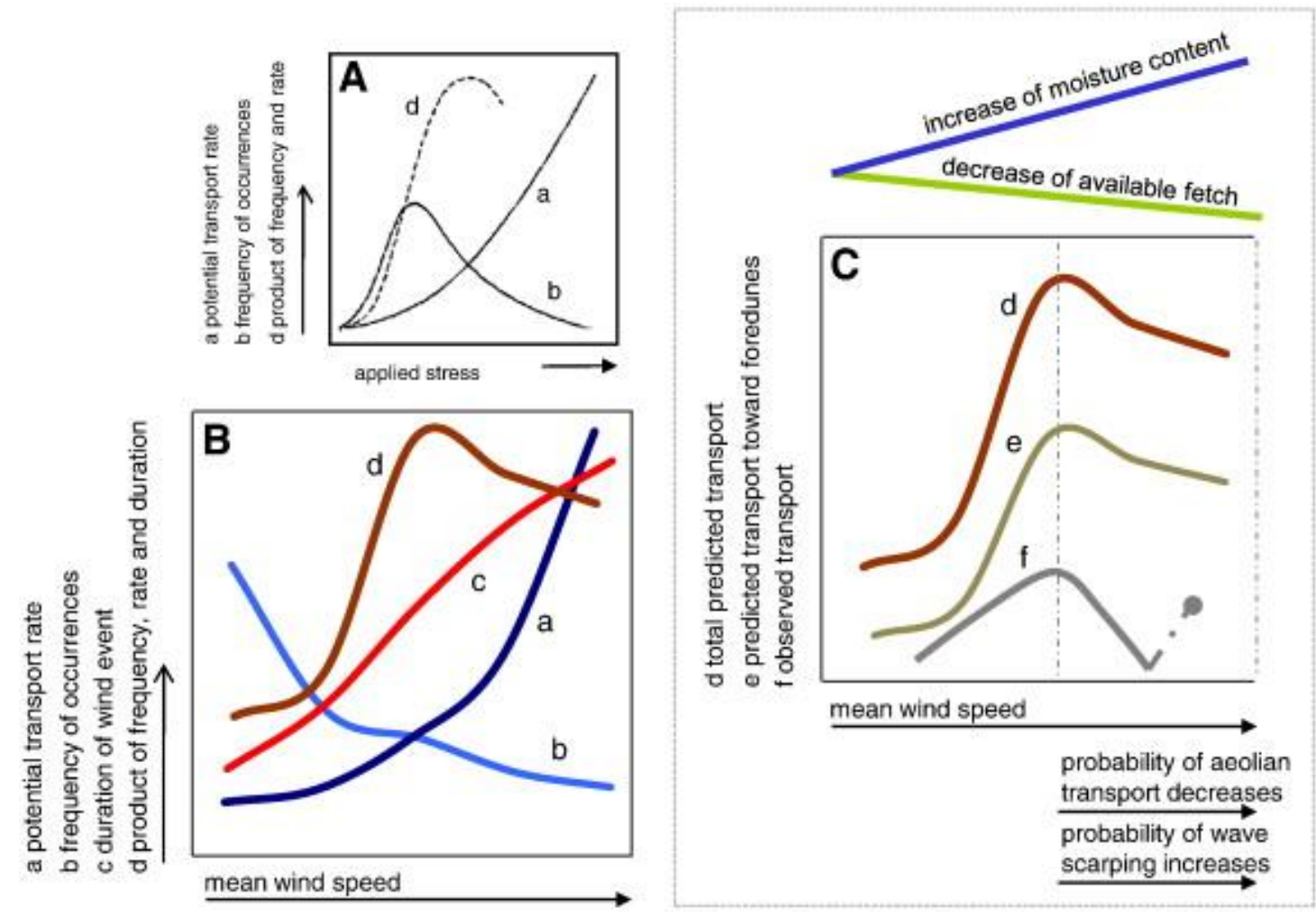

Fig. 12. A) Original model proposed by Wolman and Miller (1960) relating the frequency and magnitude of events in geomorphology; B) Modified model for wind events at Greenwich, showing the relation between wind event mean velocity and mean potential transport rate (a), frequency of wind event (b), duration of wind event (c), and product of event frequency, duration and potential sediment transport rate (d, equivalent to predicted $\mathrm{Q}$ ). Note that winds below the threshold of $6 \mathrm{~m} \mathrm{~s}^{-1}$ are not included; C) Relation between Q, Qn, and observed transport toward the foredune at Greenwich. As the wind event magnitude increased the probability of transport approaching the theoretical value decreased and the probability of wave scarping increased. 


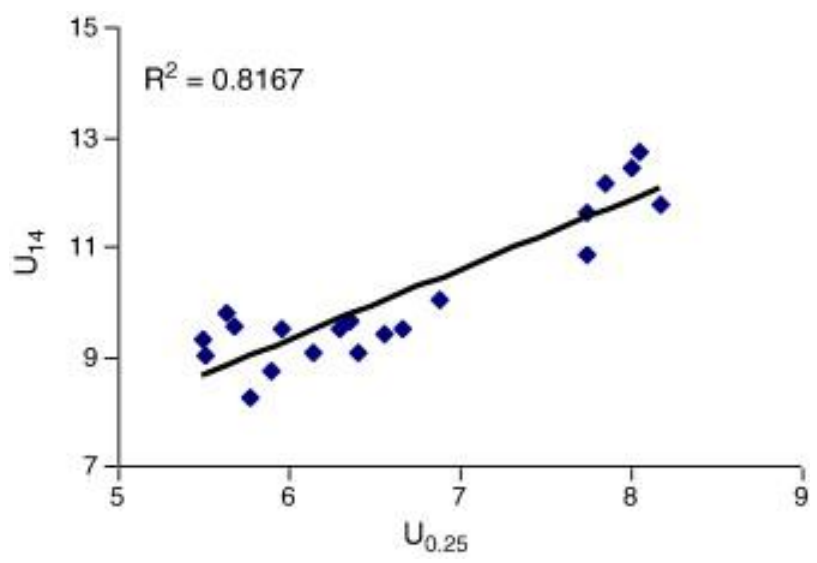

Fig. 13. Linear regression between wind speeds measured at $0.25 \mathrm{~m}$ over the beach surface with a cup anemometer $\left(\cup_{0.25}\right)$ and at 14 m over the beach surface with the 2D sonic anemometer on top of the mast $\left(\mathrm{U}_{14}\right)$. Mean values (in $\mathrm{m} \mathrm{s}^{-1}$ ) are calculated for 10 min runs of data collected during a short-term experiment in October 2007. 